\title{
Numerical simulation and feasibility assessment of acid gas injection in a carbonate formation of the Tarim Basin, China
}

\author{
Xiaoyan Zhang ${ }^{1,2}, \mathrm{Qi} \mathrm{Li}^{1,2,}{ }^{*}$, Liange Zheng ${ }^{3}$, Xiaying $\mathrm{Li}^{1,2}$, and Liang $\mathrm{Xu}^{1,2}$ \\ ${ }^{1}$ State Key Laboratory of Geomechanics and Geotechnical Engineering, Institute of Rock and Soil Mechanics, \\ Chinese Academy of Sciences, Wuhan 430071, China \\ ${ }^{2}$ University of Chinese Academy of Sciences, Beijing 100049, China \\ ${ }^{3}$ Energy Geoscience Division, Lawrence Berkeley National Laboratory, Berkeley, CA 94720, USA
}

Received: 27 June 2019 / Accepted: 23 March 2020

\begin{abstract}
An enormous amount of acid gas, containing carbon dioxide $\left(\mathrm{CO}_{2}\right)$ and hydrogen sulfide $\left(\mathrm{H}_{2} \mathrm{~S}\right)$, is generated in the exploitation of oil and gas reservoirs in the Tarim Basin, China. An appropriate management plan is required to safely dispose of the acid gas, and common strategy considered for the safe disposal of acid gas is the injection of it into deep formations - this strategy mitigates greenhouse gas emissions and avoids costs associated with desulfurization. A feasibility assessment of acid gas injection requires a detailed investigation of the potential physical and geochemical impacts. Reactive transport simulations based on the mineralogical composition and the hydrochemical characteristics of a carbonate formation in the Tarim Basin were conducted to identify the physical and geochemical interactions of acid gas with the mineral matrix and formation water. Acid gas $\left(59 \% \mathrm{CO}_{2}\right.$ and $\left.41 \% \mathrm{H}_{2} \mathrm{~S}\right)$ was injected at a constant rate of $19200 \mathrm{Nm}^{3} / \mathrm{d}$ for 25 years, and the simulation was run by the TMVR_EOSG module of the TOUGHREACT code for a period of 10000 years. The results indicate that the minimum liquid saturation is much larger than the residual water saturation, and the pressure buildup is below the allowable pressure increase. Additionally, the porosity change is found to be negligible due to the small changes in calcite and quartz in the volume fraction. From this perspective, acid gas injection in the carbonate formation of the Tarim Basin seems feasible. Furthermore, the fast breakthrough of $\mathrm{CO}_{2}$ can provide an advanced warning of a potential breakthrough of acid gas. Last, the injection rate can be increased to accelerate acid gas trapping, and the results could be used as guidance for future acid gas injection operations.
\end{abstract}

\section{Introduction}

With the increasing exploitation of sour hydrocarbon reservoirs, a growing volume of acid gas, consisting primarily of carbon dioxide $\left(\mathrm{CO}_{2}\right)$ and hydrogen sulfide $\left(\mathrm{H}_{2} \mathrm{~S}\right)$, is generated. The conventional sulfur recovery method, which converts sulfur compounds to elemental sulfur and directly emits residual $\mathrm{CO}_{2}$ into the atmosphere, can be adopted to dispose of acid gas. However, the recovered sulfur is below the commodity standard, making it difficult to sell and increasing the accumulation of hazardous waste. Furthermore, residual $\mathrm{CO}_{2}$ emissions aggravate global warming. Consequently, Acid Gas Injection (AGI) into depleted oil and gas reservoirs is gaining increasing attention as an alternative to mitigate greenhouse gas emissions and to avoid the costs of desulfurization. Actually, acid gas injection operations have been approved worldwide (British Columbia Geological Survey, 2003; Carroll et al., 2009;

\footnotetext{
* Corresponding author: qli@whrsm.ac.cn
}

Khan et al., 2013; Li et al., 2017; Miwa et al., 2002), and feasibility of AGI operations in China has been analyzed (Li et al., 2013; Liu et al., 2012). However, the implementation of acid gas injection requires a proper assessment of the effects induced by the presence of acid gas.

During acid gas injection, $\mathrm{CO}_{2}$ and $\mathrm{H}_{2} \mathrm{~S}$ both displace and dissolve in the formation waters. Afterwards, the dissolved $\mathrm{CO}_{2}$ and $\mathrm{H}_{2} \mathrm{~S}$ undergo hydrolysis reactions leading to the generation of weakly acidic solutions. Subsequently, acidic brine leads to the dissolution of the host rock minerals. Dissolved ions and minerals may also further react to precipitate carbonates and other secondary minerals (De Silva et al., 2015; Jia et al., 2016; Talman, 2015; Zhu et al., 2013). As a result, more exploration is needed in the pre-feasibility investigation phase on the potential impacts (including physical and geochemical properties) and the trapping evolution of acid gas (Bachu and Gunter, 2004; Cantucci et al., 2015; De Silva et al., 2015; Talman, 2015; Zhu et al., 2013).

Many investigations investigated the geochemical effects of acid gas injection. Knauss et al. (2005) evaluated 
the impacts of dissolved $\mathrm{CO}_{2}$, as well as a mixture of dissolved $\mathrm{CO}_{2}$ and $\mathrm{H}_{2} \mathrm{~S}$, on a geological formation. In addition, Xiao et al. (2009) and Xu et al. (2007) developed models to estimate the gas-fluid-rock interactions, in which $\mathrm{CO}_{2}$ was injected as a gas phase and $\mathrm{H}_{2} \mathrm{~S}$ was injected as an aqueous solute. As an analogue for $\mathrm{CO}_{2}$ geological storage, the results suggest that the injection of additional $\mathrm{H}_{2} \mathrm{~S}$ is very similar to the injection of pure $\mathrm{CO}_{2}$ (Knauss et al., 2005; Xiao et al., 2009; Xu et al., 2007). However, the presence of iron-bearing minerals leads to the precipitation of pyrite, which influences mineral trapping. Schaef et al. (2010) reported results from laboratory tests of various basalts reacted with water equilibrated with supercritical $\mathrm{CO}_{2}$ containing $1 \% \mathrm{H}_{2} \mathrm{~S}$ for 181 days. The results showed that very rapid precipitation of pyrite appeared to inhibit carbonate mineralization reactions. Schaef et al. (2013) continued the work of Schaef et al. (2010) by extending the duration of experiments up to 3.5 years. They found that permanent carbonate mineralization was not impaired by pyrite formation reactions, though pyrite appeared to coat the surface and halt carbonate formation in previous shorter duration tests.

The investigations mentioned above have provided significant insight into the geochemical effects of acid gas injection. However, the partitioning phenomena occurring after acid gas injection are neglected. Bachu and Bennion (2009) first carried out a series of laboratory experiments to examine the chromatographic partitioning of acid gas injected into deep saline aquifers. The experiments were conducted with $\mathrm{H}_{2} \mathrm{~S}$ as an impurity in the $\mathrm{CO}_{2}$ stream, at $2 \%, 5 \%$ and $30 \%$ concentrations under static and dynamic conditions. They found that there is a time lag between $\mathrm{CO}_{2}$ and $\mathrm{H}_{2} \mathrm{~S}$ appearing in the effluent gas. In addition, the higher the fraction of $\mathrm{H}_{2} \mathrm{~S}$ in the injection stream is, the smaller the time lag between the $\mathrm{CO}_{2}$ and $\mathrm{H}_{2} \mathrm{~S}$ breakthroughs. Then, Bachu et al. (2009) carried out numerical studies to replicate the laboratory results, including the breakthrough of $\mathrm{CO}_{2}$ appearing ahead of $\mathrm{H}_{2} \mathrm{~S}$.

Many other studies have been undertaken to investigate both the physical and geochemical effects of acid gas injection. Zheng et al. (2010) and (2013) simulated the coinjection of $\mathrm{H}_{2} \mathrm{~S}$ with $\mathrm{CO}_{2}$ into a deep saline aquifer to study the leakage of supercritical $\mathrm{CO}_{2}$ and $\mathrm{H}_{2} \mathrm{~S}$ mixtures along a preferential pathway to an overlying fresh-water aquifer and to study reactions of the gas mixture with that aquifer. They concluded that there is some delay observed between the arrival times of $\mathrm{CO}_{2}$ and $\mathrm{H}_{2} \mathrm{~S}$ into the shallow aquifer. Nevertheless, the effect does not continue very long in duration, and $\mathrm{H}_{2} \mathrm{~S}$ comigrating with $\mathrm{CO}_{2}$ is predicted to enter the aquifer once this stripping effect ceases. If there was a sufficient amount of ferrous iron supplied in the aquifer, the precipitation of pyrite could sequester a large portion of the injected sulfide. Similarly, Zhang et al. (2011) performed numerical simulations to study the coinjection of $\mathrm{H}_{2} \mathrm{~S}$ and $\mathrm{CO}_{2}$ in sandstone and carbonate formations. The chromatographic partitioning of acid gas was also observed. Moreover, they found that the presence of iron-bearing siliciclastic and carbonate was more favorable to $\mathrm{H}_{2} \mathrm{~S}$ mineral trapping. As a result, coinjection of $\mathrm{H}_{2} \mathrm{~S}$ in the
$\mathrm{CO}_{2}$ stream decreased the solubility and mineral trapping of $\mathrm{CO}_{2}$ compared to the pure $\mathrm{CO}_{2}$ injection case. Conversely, Bacon et al. (2014) found that co-sequestering $\mathrm{H}_{2} \mathrm{~S}$ along with $\mathrm{CO}_{2}$ did not noticeably modify the predicted amount of $\mathrm{CO}_{2}$ sequestered. Under this condition, up to $5 \%$ of $\mathrm{H}_{2} \mathrm{~S}$ is sequestered completely as pyrite.

Although acid gas injection has been investigated extensively, those studies only consider the effects of an $\mathrm{H}_{2} \mathrm{~S}$ impurity in $\mathrm{CO}_{2}$ storage, including the partitioning phenomena of impure $\mathrm{CO}_{2}$ storage, geochemical effects by coinjected $\mathrm{H}_{2} \mathrm{~S}$ and $\mathrm{CO}_{2}$ storage capacity influenced by $\mathrm{H}_{2} \mathrm{~S}$. The $\mathrm{H}_{2} \mathrm{~S}$ concentration in the injected $\mathrm{CO}_{2}$ stream is lower than $10 \%$. However, the $\mathrm{H}_{2} \mathrm{~S}$ concentration in acid gas injection operations varies from $2 \%$ to $85 \%$ (British Columbia Geological Survey, 2003). Essentially, water in the porous media becomes saturated with more soluble gas more quickly. In addition, a higher fraction of $\mathrm{H}_{2} \mathrm{~S}$ in the acid gas results in an earlier breakthrough of both $\mathrm{CO}_{2}$ and $\mathrm{H}_{2} \mathrm{~S}$ (Bachu and Bennion, 2009; Bachu et al., 2009). Additionally, more site-specific studies considering the variability and uncertainty of key hydrogeological and geochemical parameters are needed (Zheng et al., 2013). Thus, the feasibility of acid gas injection in the Tarim Basin is urgently needed that considers the effect of acid gas composition $\left(59 \% \mathrm{CO}_{2}\right.$ and $\left.41 \% \mathrm{H}_{2} \mathrm{~S}\right)$, mineral composition, formation water chemistry and reservoir physical conditions.

In the present study, a numerical simulation was conducted to investigate the feasibility assessment of acid gas injection in a carbonate formation of the Tarim Basin. Four aspects were mainly considered: (1) the distribution of the acid gas plume and partitioning phenomenon occurring between $\mathrm{CO}_{2}$ and $\mathrm{H}_{2} \mathrm{~S} ;(2)$ the pressure buildup due to acid gas injection; (3) the geochemical effects and corresponding effects on the porosity of the reservoir; and (4) the trapping evolution of injected acid gas, including the acid gas mixture, $\mathrm{CO}_{2}$ component and $\mathrm{H}_{2} \mathrm{~S}$ component. Finally, we considered the uncertainty of key parameters, including the injection rate, permeability and porosity, and performed a sensitivity analysis to investigate their impact on the evolution of gas saturation, pressure buildup and entrapment of injected acid gas.

\section{Geological setting}

The Tarim Basin is the largest sedimentary basin in China, with an area of approximately $560000 \mathrm{~km}^{2}$. The formation and evolution of the basin can be divided into four main periods: Sinian-Cambrian, Ordovician, early Permian, and Cretaceous (Chen et al., 1997). As the largest petroliferous superposed basin in China, it has been well studied geologically (Chen et al., 1997; Gao et al., 2016; Jia et al., 2016; Shen et al., 2016), however, its potential as a site for acid gas injection has not yet been investigated. In this section, the geological setting of the Tahe oilfield is briefly addressed in Section 2.1 and the selected injection reservoir is presented in Section 2.2. 


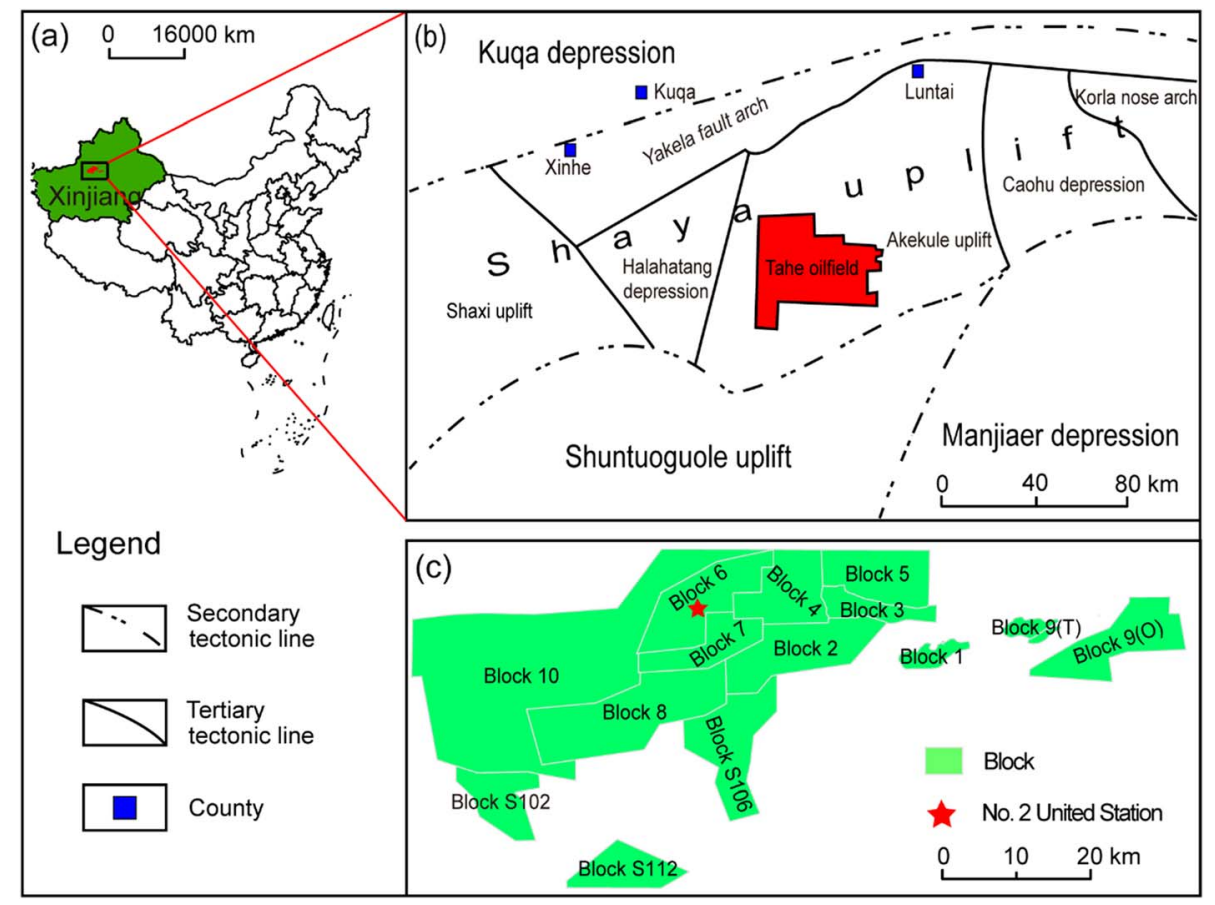

Fig. 1. Location map of the No. 2 United Station at the Tahe oilfield, Tarim Basin, Xinjiang, China.

\subsection{Tahe oilfield}

The Tahe oilfield, located in the northern Tarim Basin (Fig. 1a), is in the southwest Akekule uplift in the Shaya uplift. It is surrounded by the Caohu sag to the east, the Halahatang sag to the west, the Manjiaer sag to the south and the Yakela uplift to the north (Fig. 1b). The origin of petroleum in the Tahe oilfield is mainly CambrianOrdovician source rocks. To date, the Tahe oilfield, with its 12 blocks (Fig. 1c), is the largest oilfield found in the Paleozoic marine carbonate rocks in China. Petroleum is recovered from the Ordovician carbonate rocks and the Carboniferous and Triassic sandstones ( $\mathrm{Yu}$ et al., 2011).

\subsection{Carbonate reservoir}

The No. 2 United Station is located in Block 6 of the Tahe oilfield (Fig. 1c). It generates a large amount of acid gas as a byproduct during crude oil processing. To reduce greenhouse gas emissions and reduce the costs of desulfurization, the SINOPEC intends to dispose of acid gas in depleted oil and gas fields. A preliminary investigation led to the selection of well TH75CX as the injection well near the No. 2 United Station (Fig. 2).

A $5500 \mathrm{~m}$ deep borehole site investigation revealed that the Ordovician stratigraphic sequence in the well includes the Lower-Middle Ordovician Yingshan Group $\left(\mathrm{O}_{1-2 y}\right)$. The Yingshan Group is the main oil and gas reservoir with a thickness of $51 \mathrm{~m}$. As a carbonate rock reservoir, it mainly consists of open platform facies limestone. At present, the carbonate rock reservoir is in the end period of production and is considered the potential disposal site of acid gas.

\section{Numerical approach}

\subsection{Numerical toolbox}

A numerical simulation of this study was performed by the TMVR-EOSG (unpublished) simulator, which was developed from TMVOC-REACT (Zheng et al., 2010, 2013). As with TMVOC-REACT, the simulator links TMVOC (Pruess and Battistelli, 2002) and TOUGHREACT (Xu et al., 2012) by replacing the fluid and heat flow parts in TOUGHREACT with TMVOC. To analyze the coupling process occurring between flow and chemistry, gas partial pressures and fugacity coefficients calculated by the flow module (TMVOC) are passed to the geochemical module (TOUGHREACT). The routine GASEOS (Reagan, 2006) is also incorporated to calculate gas partial pressures and fugacity coefficients in gas mixtures. Temporal changes in porosity and permeability owing to mineral dissolution and precipitation are fed back to the fluid flow module by lagging one-time steps. Moreover, TMVR-EOSG additionally incorporates a new Equation of State (EOS), namely, Ziabakhsh-Ganji and Kooi EOS (Ziabakhsh-Ganji and Kooi, 2012) with binary interaction coefficients for $\mathrm{CO}_{2}-\mathrm{SO}_{2}, \mathrm{CO}_{2}-\mathrm{H}_{2} \mathrm{~S}, \mathrm{CO}_{2}-\mathrm{CH}_{4}$ and $\mathrm{CO}_{2}-\mathrm{N}_{2}$. The new EOS can simulate the impacts of gas mixtures including $\mathrm{CO}_{2}, \mathrm{SO}_{2}, \mathrm{H}_{2} \mathrm{~S}, \mathrm{CH}_{4}$ and $\mathrm{N}_{2}$, and allow for an accurate and efficient modeling of the thermodynamic equilibrium of gas mixtures and brines.

\subsection{Model setup}

To investigate the potential physical and geochemical interactions occurring among acid gas, formation water, and rock minerals, a one-dimensional (1D) radial model 


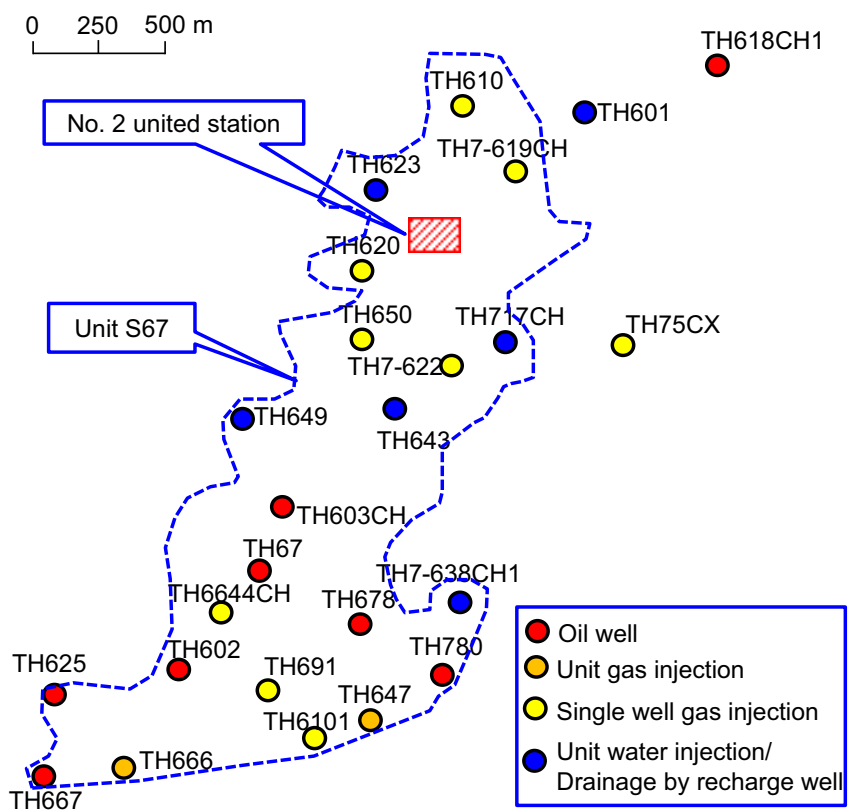

Fig. 2. The potential area for acid gas reinjection.

(Fig. 3) was used in the simulation. According to the underground conditions of the Yingshan Group, the 1D model was set as a homogeneous carbonate formation with a thickness of $50 \mathrm{~m}$. In the lateral direction, the model covered a $10000 \mathrm{~m}$ radial distance and 130 radial grid elements with the grid spacing gradually increasing away from the injection well. The volume of the outer grid element is specified as a large value of $10^{30} \mathrm{~m}^{3}$ to represent an infinite lateral extent.

Based on the acid gas injection project designed by the SINOPEC, the acid gas injection rate is $19200 \mathrm{Nm}^{3} / \mathrm{d}$ for 25 years. The original flue gas generated by the No. 2 United Station includes $0.19 \mathrm{~mol} \%$ methane $\left(\mathrm{CH}_{4}\right)$, $0.05 \mathrm{~mol} \%$ ethane $\left(\mathrm{C}_{2} \mathrm{H}_{6}\right), 0.03 \mathrm{~mol} \%$ propane $\left(\mathrm{C}_{3} \mathrm{H}_{8}\right)$, $1.47 \mathrm{~mol} \%$ nitrogen $\left(\mathrm{N}_{2}\right), 46.77 \mathrm{~mol} \% \mathrm{CO}_{2}, 42.3 \mathrm{~mol} \%$ $\mathrm{H}_{2} \mathrm{~S}$ and $9.2 \mathrm{~mol} \%$ water $\left(\mathrm{H}_{2} \mathrm{O}\right)$. Multistage pressurization and dehydration caused water extraction prior to acid gas injection. The total percentage for $\mathrm{CH}_{4}, \mathrm{C}_{2} \mathrm{H}_{6}, \mathrm{C}_{3} \mathrm{H}_{8}$ and $\mathrm{N}_{2}$ is just $1.92 \mathrm{~mol} \%$, and thus, only $\mathrm{CO}_{2}$ and $\mathrm{H}_{2} \mathrm{~S}$ are the dominant components considered in our numerical simulation.

Acid gas was injected at a constant rate of $0.229 \mathrm{~kg} / \mathrm{s}$ for $\mathrm{CO}_{2}$ and $0.160 \mathrm{~kg} / \mathrm{s}$ for $\mathrm{H}_{2} \mathrm{~S}$ in the simulation. In the simulation, a continuous gas injection was applied for a period of 25 years, and the geochemical transport simulations were run for 10000 years.

\subsection{Initial conditions}

The initial reservoir pressure is $600 \mathrm{bar}$, and the formation temperature is $128^{\circ} \mathrm{C}$ at a depth of $5500 \mathrm{~m}$. However, due to limitations of existing studies, the experimental data for $\mathrm{H}_{2} \mathrm{~S}$ solubility were within a relatively high temperature $\left(321{ }^{\circ} \mathrm{C}\right.$ ) and low pressure (210 bar) (Zheng et al., 2010). As a result, the simulator is applicable at moderate

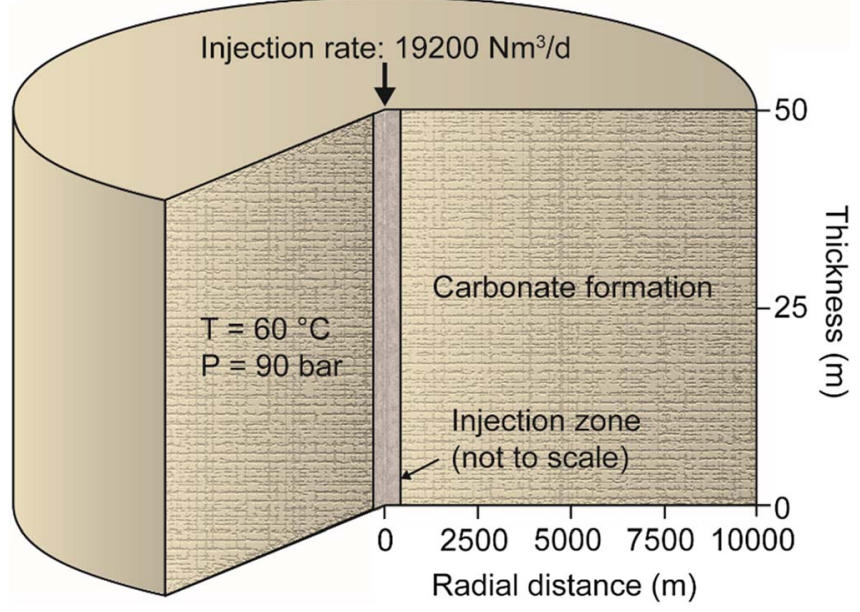

Fig. 3. Schematic diagram of the 1D radial model.

temperatures $\left(<200{ }^{\circ} \mathrm{C}\right)$ and pressures $(<200 \mathrm{bar})$. The convergence will probably worsen if the simulation is run under high-temperature and high-pressure conditions. More importantly, the accuracy of the calculation will decrease, because the solubility of a component present in different phases that is currently implemented in TMVR-EOSG is only valid under low temperature and pressure (Zheng et al., 2010, 2013). According to the phase-equilibrium properties of the system (Bierlein and Kay, 1953), the critical temperature and critical pressure are approximately $57^{\circ}$ $\mathrm{C}$ and 82 bar, respectively. To ensure the supercritical state of acid gas, the pressure and temperature are set as 90 bar and $60{ }^{\circ} \mathrm{C}$ in the simulation, respectively.

The initial mineral composition was derived from laboratory studies of the Yingshan Group carbonate by X-Ray Diffraction (XRD) analysis. The reservoir comprises 97\% volume calcite and 3\% volume quartz. The hydrogeologic parameters used in the $1 \mathrm{D}$ radial model are listed in Table 1. Petrophysical properties such as porosity and permeability of rock formations were inferred from the statistical data summarized in the literature (Liang et al., 2016). The evaluation index for porosity is the cumulative amount of single well oil production (Tab. 2). Since the oil production of $\mathrm{TH} 75 \mathrm{CX}$ is $13668 \mathrm{t}$, the porosity is set at 0.2 . The permeability is assumed to be the average value of $5 \times 10^{-12} \mathrm{~m}^{2}$ in the simulation. Due to the lack of available data, other required hydrogeological parameters are specified according to the literature (Xu et al., 2007; Zhang et al., 2011).

Water chemical analysis results are available for the water samples taken from the injection well TH75CX. The Yingshan Formation water is dominated by $\mathrm{CaCl}_{2}$, and the aqueous solution composition is shown in Table 3.

\subsection{Kinetic parameters of mineral dissolution and precipitation}

The reversible and fast geochemical reactions can be described properly by the chemical equilibrium model. However, a kinetic model is necessary to represent irreversible 
Table 1. Hydrogeological parameters for the 1D radial model.

\begin{tabular}{lc}
\hline Parameters & Value \\
\hline Permeability $\left(\mathrm{m}^{2}\right)$ & $5 \times 10^{-12}$ \\
Porosity & 0.2 \\
Tortuosity & 0.3 \\
Pore compressibility $\left(\mathrm{Pa}^{-1}\right)$ & $1 \times 10^{-8}$ \\
Diffusivity $\left(\mathrm{m}^{2} / \mathrm{s}\right)$ & $1 \times 10^{-9}$ \\
Rock grain density $\left(\mathrm{kg} / \mathrm{m}^{3}\right)$ & 2600 \\
Rock grain specific heat $\left(\mathrm{J} /\left(\mathrm{kg}{ }^{\circ} \mathrm{C}\right)\right)$ & 920 \\
Formation heat conductivity $\left(\mathrm{W} /\left(\mathrm{m}{ }^{\circ} \mathrm{C}\right)\right)$ & 2.51 \\
& \\
Relative permeability model & $S^{*}=\left(S_{\mathrm{l}}-S_{\mathrm{lr}}\right) /\left(1-S_{\mathrm{lr}}\right)$ \\
Liquid $($ van Genuchten $): k_{\mathrm{rl}}=\sqrt{S^{*}}\left\{1-\left(1-\left[S^{*}\right]^{1 / m}\right)^{m}\right\}^{2}$ & $S_{\mathrm{lr}}=0.30$ \\
$S_{\mathrm{lr}}:$ residual water saturation & $m=0.457$ \\
$m:$ exponent & \\
Gas $($ Corey $):$ & $S_{\mathrm{l}}^{2}=\left(S_{\mathrm{l}}-S_{\mathrm{lr}}\right) /\left(S_{\mathrm{l}}-S_{\mathrm{lr}}-S_{\mathrm{gr}}\right)$ \\
$k_{\mathrm{rg}}=\left(1-\hat{S}^{2}\left(1-\hat{S}^{2}\right)\right.$ & $S_{\mathrm{gr}}=0.05$ \\
$S_{\mathrm{gr}}:$ residual gas saturation & \\
Capillary pressure model $(\mathrm{van}$ Genuchten $)$ & $S^{*}=\left(S_{\mathrm{l}}-S_{\mathrm{lr}}\right) /\left(1-S_{\mathrm{lr}}\right)$ \\
$P_{\text {cap }}=-P_{0}\left(\left[S^{*}\right]^{-1 / m}-1\right)^{1-m}$ & $S_{\mathrm{lr}}=0.00$ \\
$S_{\mathrm{lr}}:$ residual water saturation & $m=0.457$ \\
$m:$ exponent & $P_{0}=19.61$ \\
$P_{0}:$ strength coefficient $(\mathrm{kPa})$ & \\
\hline
\end{tabular}

Table 2. Porosity in the carbonate reservoir of the Tahe oilfield, Xinjiang, China.

\begin{tabular}{cc}
\hline Cumulative oil production $\left(N_{\mathrm{p}}\right)$ & Porosity (\%) \\
\hline$N_{\mathrm{p}}>15 \times 10^{4} \mathrm{t}$ & $50 \sim 60$ \\
$4.5 \times 10^{4} \mathrm{t}<N_{\mathrm{p}}<15 \times 10^{4} \mathrm{t}$ & $30 \sim 40$ \\
$N_{\mathrm{p}}<4.5 \times 10^{4} \mathrm{t}$ & 20 \\
\hline
\end{tabular}

heterogeneous reactions, for instance, mineral carbonation (Marini, 2006). A kinetic model is adopted by TOUGHREACT based on the transition state theory, where the kinetic rate is expressed as (Lasaga et al., 1994):

$$
r_{\mathrm{n}}= \pm k_{\mathrm{n}} A_{\mathrm{n}}\left|1-\Omega_{\mathrm{n}}^{\theta}\right|^{\eta}
$$

where $r_{\mathrm{n}}$ is the kinetic rate (positive values denote mineral dissolution and negative values denote precipitation), $k_{\mathrm{n}}$ is the kinetic rate constant $\left(\mathrm{mol} \mathrm{m}^{-2} \mathrm{~s}^{-1}\right), A_{\mathrm{n}}$ is the specific surface area $\left(\mathrm{m}^{2} \mathrm{~kg} \mathrm{w}^{-1}\right)$, and $\Omega_{\mathrm{n}}$ is the kinetic mineral saturation ratio. The parameters $\theta$ and $\eta$ are set to one in this study as in common practice.

The kinetic rate constant $k_{\mathrm{n}}$ is influenced not only by temperature, but also by different chemistry mechanisms (acid, neutral and base mechanisms). For many minerals,
Table 3. Initial water chemistry of the Yingshan Formation, Xinjiang area, China.

\begin{tabular}{lc}
\hline Component & Concentration $(\mathrm{mol} / \mathrm{L})$ \\
\hline $\mathrm{Na}^{+}$ & $2.580 \times 10^{-1}$ \\
$\mathrm{Ca}^{2+}$ & $1.602 \times 10^{-1}$ \\
$\mathrm{Mg}^{2+}$ & $5.165 \times 10^{-3}$ \\
$\mathrm{Cl}^{-}$ & $3.315 \times 10^{-1}$ \\
$\mathrm{HCO}_{3^{-}}$ & $4.076 \times 10^{-4}$ \\
$\mathrm{SO}_{4}{ }^{2-}$ & $1.821 \times 10^{-4}$ \\
$\mathrm{SiO}_{2(\mathrm{aq})}$ & $4.570 \times 10^{-4}$ \\
$\mathrm{pH}$ & 6.8 \\
\hline
\end{tabular}

the kinetic rate constant $k_{\mathrm{n}}$ is summarized as (Lasaga et al., 1994; Palandri and Kharaka, 2004):

$$
\begin{aligned}
k_{\mathrm{n}}= & k_{25}^{\mathrm{nu}} \exp \left[\frac{-E_{\mathrm{a}}^{\mathrm{nu}}}{R}\left(\frac{1}{T}-\frac{1}{298.15}\right)\right]+k_{25}^{\mathrm{H}} \\
& \times \exp \left[\frac{-E_{\mathrm{a}}^{\mathrm{H}}}{R}\left(\frac{1}{T}-\frac{1}{298.15}\right)\right] a_{\mathrm{H}}^{n_{\mathrm{H}}}+k_{25}^{\mathrm{OH}} \\
& \times \exp \left[\frac{-E_{\mathrm{a}}^{\mathrm{OH}}}{R}\left(\frac{1}{T}-\frac{1}{298.15}\right)\right] a_{\mathrm{OH}}^{n_{\mathrm{OH}}}
\end{aligned}
$$


Table 4. Kinetic parameters for minerals.

\begin{tabular}{|c|c|c|c|c|c|c|c|c|c|}
\hline \multirow[t]{3}{*}{ Mineral } & \multirow[t]{3}{*}{$A^{\prime}\left(\mathrm{cm}^{2} / \mathrm{g}\right)$} & \multicolumn{8}{|c|}{ Parameters for the kinetic rate law } \\
\hline & & \multicolumn{2}{|c|}{ Neutral mechanism } & \multicolumn{3}{|c|}{ Acid mechanism } & \multicolumn{3}{|c|}{ Base mechanism } \\
\hline & & $\begin{array}{c}k_{25} \\
\left(\mathrm{~mol} / \mathrm{m}^{2} / \mathrm{s}\right)\end{array}$ & $\begin{array}{c}E_{\mathrm{a}} \\
(\mathrm{kJ} / \mathrm{mol})\end{array}$ & $\begin{array}{c}k_{25} \\
\left(\mathrm{~mol} / \mathrm{m}^{2} / \mathrm{s}\right)\end{array}$ & $\begin{array}{c}E_{\mathrm{a}} \\
(\mathrm{kJ} / \mathrm{mol})\end{array}$ & $n_{\mathrm{H}}$ & $\begin{array}{c}k_{25} \\
\left(\mathrm{~mol} / \mathrm{m}^{2} / \mathrm{s}\right)\end{array}$ & $\begin{array}{c}E_{\mathrm{a}} \\
(\mathrm{kJ} / \mathrm{mol})\end{array}$ & $n_{\mathrm{OH}}$ \\
\hline Calcite & 9.8 & $1.549 \times 10^{-6}$ & 23.5 & $5.012 \times 10^{-1}$ & 14.4 & 1.0 & $3.311 \times 10^{-4}$ & 35.1 & $\overline{1.0}$ \\
\hline Quartz & 9.1 & $1.023 \times 10^{-14}$ & 87.7 & & & & & & \\
\hline
\end{tabular}

where superscripts or subscripts $\mathrm{nu}, \mathrm{H}$, and $\mathrm{OH}$ indicate neutral, acid and base mechanisms, respectively. $k_{25}$ is the rate constant at $25^{\circ} \mathrm{C}, E_{\mathrm{a}}$ is the activation energy, $R$ is the gas constant, $T$ is the absolute temperature, $a$ is the activity of the species, and $n$ is the power term (constant). The dissolution rate is assumed to be equal to the precipitation rate for all minerals. In this study, the parameters for the kinetics of dissolution and precipitation listed in Table 4 are taken from the literature (Marini, 2006; Zhu et al., 2013).

In the geochemical reaction process, only a portion of the mineral surface can be dissolved. The surface area directly involved in mineral dissolution and precipitation by the solid unit mass is called the specific surface area. TOUGHREACT uses the following relationship to compute reactive surface areas of minerals (Xu et al., 2012):

$$
A_{\mathrm{r}}=\left(V_{\text {frac }} A_{\mathrm{m}}+A_{\mathrm{prc}}\right) / C_{\mathrm{w}}
$$

where $A_{\mathrm{r}}$ is the effective reactive surface area of minerals in units of $\mathrm{m}^{2}$ mineral $/ \mathrm{kg}_{\text {water }}$ for input into the kinetic rate laws (Eq. (2)), $A_{\mathrm{m}}$ is the surface area in units of $\mathrm{m}^{2}$ mineral $\mathrm{m}^{3}$ mineral, $A_{\mathrm{prc}}$ is the precursor surface area in units of $\mathrm{m}^{2}{ }_{\text {mineral }} / \mathrm{m}^{3}$ medium, $V_{\text {frac }}$ is the mineral volume fraction in $\mathrm{m}^{3}$ mineral $/ \mathrm{m}^{3}$ medium and $C_{\mathrm{w}}$ is the wetted-surface conversion factor in units of $\mathrm{kg}_{\text {water }} / \mathrm{m}^{3}$ medium. $A_{\mathrm{m}}, V_{\text {frac }}$ and $C_{\mathrm{w}}$ change during the course of a simulation as minerals dissolve and precipitate and as the liquid saturation of the medium fluctuates.

In terms of minerals in a rock, surface areas in units of $\mathrm{cm}^{2} / \mathrm{g}$ can be calculated from

$$
A^{\prime}=100 / \rho_{\mathrm{m}}=100 A M_{\mathrm{m}} / V_{\mathrm{m}}
$$

where $A$ is the surface area in units of $\mathrm{cm}^{2} / \mathrm{g}, \rho_{\mathrm{m}}$ is the mineral density in $\mathrm{g} / \mathrm{cm}^{3}, M \mathrm{~m}$ is the molecular weight in $\mathrm{mol} / \mathrm{g}, V \mathrm{~m}$ is the molar volume in $\mathrm{cm}^{3} / \mathrm{mol}$, and $A^{\prime}$ is the specific reactive surface area specified in the simulation. In this study, $A$ ' used in the simulations is based on the literature (Xu et al., 2007; Zhu et al., 2013), as shown in Table 4.

As a result of mineral precipitation and dissolution, the volume of the matrix changes. In TOUGHREACT, porosity changes are directly tied to volume changes and taken in the code as follows (Xu et al., 2012):

$$
\phi=1-\sum_{m-1}^{n m} f r_{\mathrm{m}}-f r_{\mathrm{u}}
$$

where $n m$ is the number of minerals, $f r_{\mathrm{m}}$ is the volume fraction of mineral $m$ in the rock $\left(V_{\text {mineral }} / V_{\text {medium }}\right.$, including porosity), and $f r_{\mathrm{u}}$ is the volume fraction of the nonreactive rock. As the $f r_{\mathrm{m}}$ of each mineral changes, the porosity is recalculated at each time step.

Several options are available in TOUGHREACT to calculate permeability changes as a result of mineral precipitation and dissolution. In this study, it is assumed that permeability does not change during the course of simulation.

\section{Results}

\subsection{Similarity solution of the simplified radial flow}

In the numerical simulation, 1D radial flow, infinite and uniform aquifer, and constant injection rate were specified. Under these conditions, the results are expected to be selfsimilar and can be plotted against the similarity variable $r^{2} / t$. The self-similarity of the numerical results is a good method of assessing the space and time discretization (Pruess and García, 2002; Pruess and Müller, 2009). Figure 4 confirms that the gas saturation and pressure profiles at 1 year and 25 years are self-similar.

Figure 4 shows that there are two distinct regions. The inner region $\left(r^{2} / t<1.35 \times 10^{-4} \mathrm{~m}^{2} / \mathrm{s}\right)$ is a two-phase (liquid-gas) zone, and the outer region $\left(r^{2} / t>1.35 \times\right.$ $10^{-4} \mathrm{~m}^{2} / \mathrm{s}$ ) is a single-phase liquid condition. The maximum gas saturation is 0.27 , which indicates that the injection of acid gas only partially displaces the resident formation brine. The minimum liquid saturation is 0.73 . It is noted that the pressure change has the same transition point as the gas saturation at $r^{2} / t=1.35 \times 10^{-4} \mathrm{~m}^{2} / \mathrm{s}$. The maximum pressure caused by acid gas injection is 90.28 bar. Pressure buildup occurs on a large scale when massive acid gas is injected into the formation, and the effect occurring in the two-phase zone is more pronounced than in the singlephase zone.

\subsection{Acid gas migration}

To better understand the process of acid gas migration, selected information is presented in graphical form as a function of radial distance from the injection wellbore at discrete time intervals of $0.01,1$, and 25 years during the injection period, and 100, 1000, and 10000 years during the postinjection period. The evolution of gas saturation 


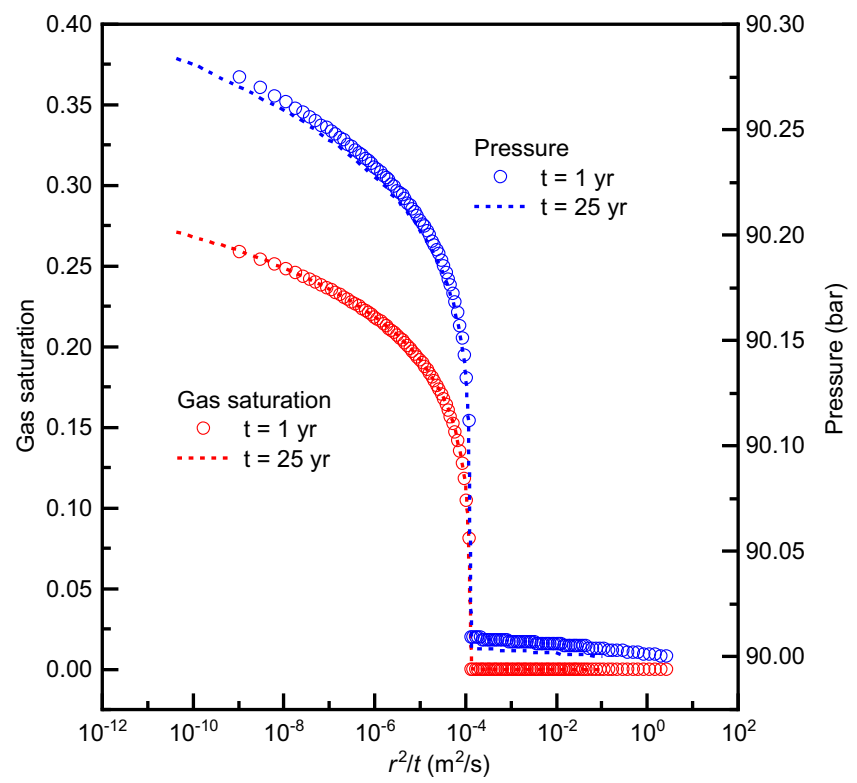

Fig. 4. Simulated gas saturation and pressure as a function of the similarity variable.

and mass fractions of the acid gas components $\left(\mathrm{CO}_{2}\right.$ and $\mathrm{H}_{2} \mathrm{~S}$ ) in gas and aqueous phases is shown in Figures 5 and 6 , respectively.

The formation is initially full of brine, and the injection of acid gas into the formation invades the pore space. Under the control of the pressure gradient and capillary forces, the resident brine located near the wellbore will be displaced and will migrate into the surroundings. The displacement is a drainage process in terms of the relevant displacement characteristics of acid gas and brine. The acid gas displacement fronts migrate approximately 6, 60, and $300 \mathrm{~m}$ at $0.01,1$, and 25 years, respectively, during injection, as shown in Figure 5; in the vicinity of the injection well, the maximum gas saturations reach $0.23,0.26$, and 0.27 , respectively; correspondingly, the minimum liquid saturations during injection are $0.77,0.74$, and 0.73 , respectively, which are much larger than the residual water saturation $\left(s_{\mathrm{lr}}=0.3\right)$.

During the postinjection period, the main displacement is a mixing process of drainage and imbibition processes. On the one hand, acid gas migrates farther under the pressure gradient. At 100 years, the acid gas displacement front migrates approximately $343 \mathrm{~m}$ (Fig. 5). On the other hand, the capillary pressure serves as a driving force to induce a backflow of brine toward the injection point. In addition, the injected acid gas gradually dissolves in the formation water. Thus, the gas saturation decreases to 0.09 at 100 years. After 1000 years, the acid gas-displacement front stops progressing forward, and the main displacement occurring is the imbibition process. The system has a tendency to reach equilibrium when gas saturation decreases approximately to the residual gas saturation of 0.05 .

The evolution of the $\mathrm{CO}_{2}$ and $\mathrm{H}_{2} \mathrm{~S}$ mass fractions in the gas and aqueous phases at different times is shown in

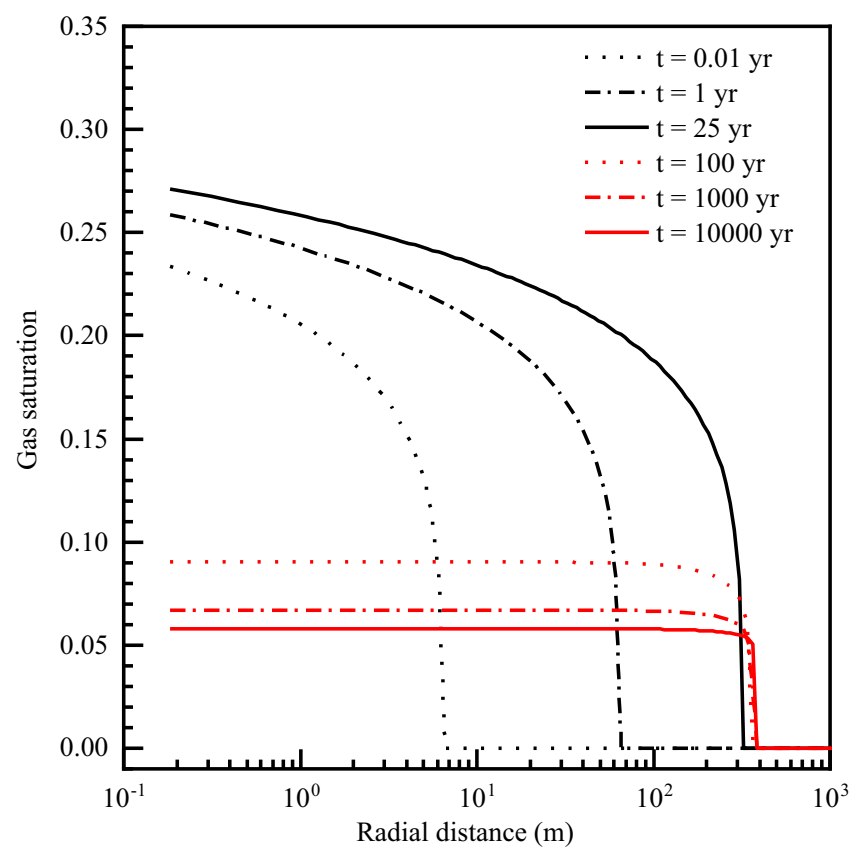

Fig. 5. Evolution of gas saturation at different times.

Figure 6. In terms of the mass fractions dissolved in the aqueous phase, the distances of the maximum $\mathrm{CO}_{2}$ mass fraction are $6.6,65.3$, and $323.7 \mathrm{~m}$ at $0.01,1$, and 25 years, respectively, and those of $\mathrm{H}_{2} \mathrm{~S}$ are $4.1,43.6$, and $216.3 \mathrm{~m}$ at $0.01,1$, and 25 years, respectively, during injection. During the postinjection period, the distance of the maximum $\mathrm{CO}_{2}$ mass fraction dissolved in the aqueous phase is $363.3 \mathrm{~m}$ at 100 years, and the distance of the maximum $\mathrm{H}_{2} \mathrm{~S}$ mass fraction dissolved in the aqueous phase at 100 years is $229.1 \mathrm{~m}$. Because the acid gas displacement front does not progress forward after almost 1000 years (Fig. 5), the distances of the maximum $\mathrm{CO}_{2}$ and $\mathrm{H}_{2} \mathrm{~S}$ mass fractions dissolved in the aqueous phase remain at 384.9 and $229.1 \mathrm{~m}$, respectively. The maximum dissolved $\mathrm{CO}_{2}$ mass fraction is achieved at a longer distance than that of the maximum dissolved $\mathrm{H}_{2} \mathrm{~S}$ mass fraction. In other words, the displacement distance of $\mathrm{CO}_{2}$ is longer than $\mathrm{H}_{2} \mathrm{~S}$ in the aqueous phase at any time.

For the mass fraction in the gas phase, the changing process has similar characteristics to the mass fraction in the aqueous phase. The distances of the maximum $\mathrm{CO}_{2}$ mass fraction are $6.6,65.3$, and $323.7 \mathrm{~m}$ at $0.01,1$, and 25 years, respectively, and those of $\mathrm{H}_{2} \mathrm{~S}$ are $3.453,38.8$, and $192.9 \mathrm{~m}$ at $0.01,1$, and 25 years, respectively, during injection. During the postinjection period, the distance of the maximum $\mathrm{CO}_{2}$ mass fraction in the gas phase is $343 \mathrm{~m}$ at 100 years, and $\mathrm{H}_{2} \mathrm{~S}$ is $204.3 \mathrm{~m}$. The distance of the maximum $\mathrm{CO}_{2}$ mass fraction and $\mathrm{H}_{2} \mathrm{~S}$ in the gas phase remains at 363.3 and $204.3 \mathrm{~m}$, respectively, after 1000 years. Thus, the displacement distance of $\mathrm{CO}_{2}$ is longer than $\mathrm{H}_{2} \mathrm{~S}$ in the gas phase at any time.

Additionally, the maximum $\mathrm{CO}_{2}$ mass fraction in the aqueous phase is 0.04 , and then decreases to 0.023 when the $\mathrm{H}_{2} \mathrm{~S}$ mass fraction increases to 0.043 . The results 

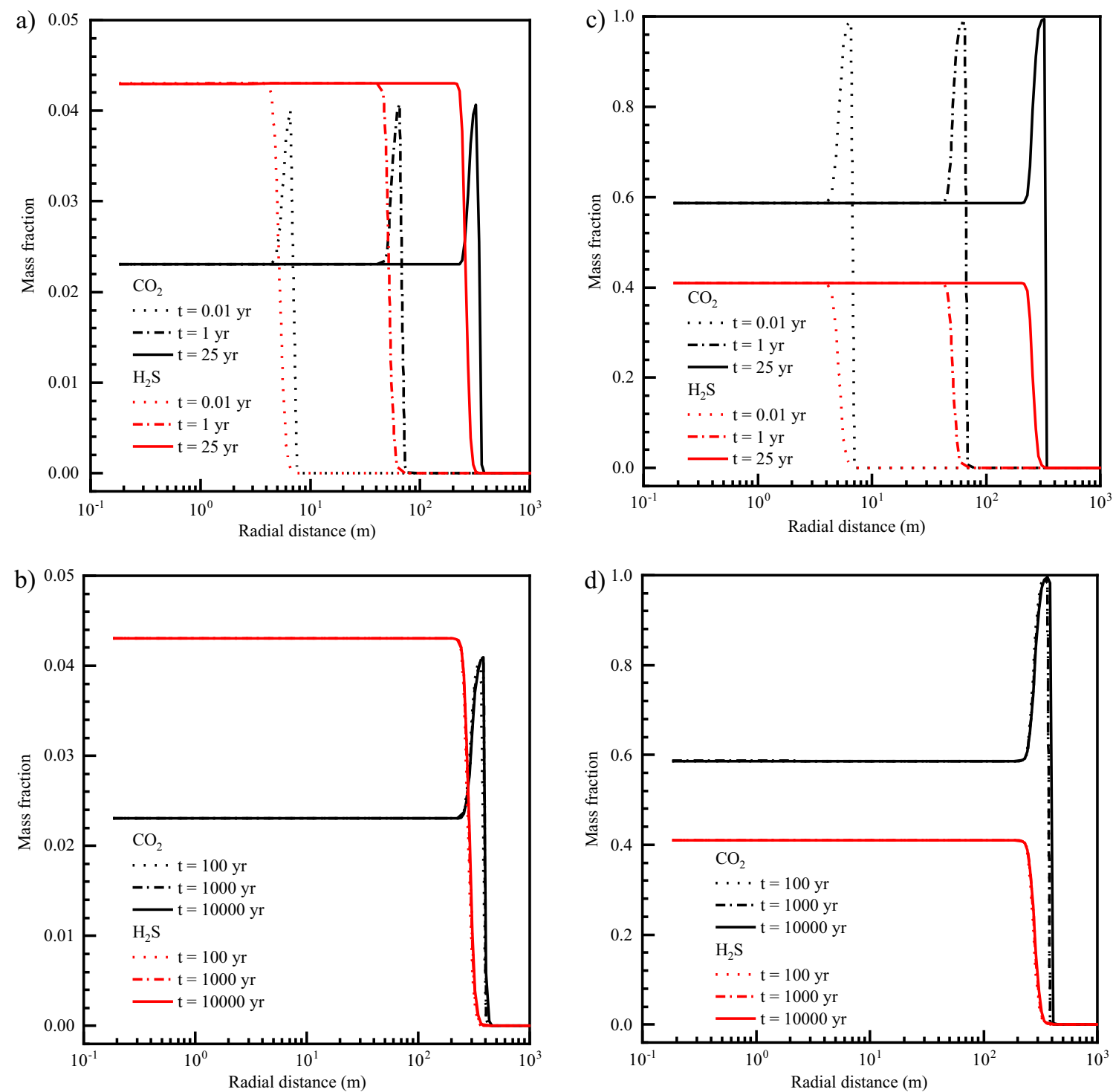

Fig. 6. Evolution of $\mathrm{CO}_{2}$ and $\mathrm{H}_{2} \mathrm{~S}$ mass fractions (a) in the aqueous phase during injection, (b) in the aqueous phase during postinjection, (c) in the gas phase during injection, and (d) in the gas phase during postinjection.

indicate that the solubility of $\mathrm{H}_{2} \mathrm{~S}$ in formation water is two times higher than that of $\mathrm{CO}_{2}$. In the gas phase, the maximum $\mathrm{CO}_{2}$ mass fraction decreases from 1 to 0.59 (the $\mathrm{CO}_{2}$ mass fraction in the injected acid gas) when the $\mathrm{H}_{2} \mathrm{~S}$ mass fraction increases to 0.41 (the $\mathrm{H}_{2} \mathrm{~S}$ mass fraction in the injected acid gas). This change occurs because there is a time lag in the breakthrough front between $\mathrm{CO}_{2}$ and $\mathrm{H}_{2} \mathrm{~S}$.

\subsection{Pressure buildup}

When acid gas is injected into deep formations, the invasion of acid gas in pore space will cause pressure buildup. Moreover, the pressure gradient that arises from acid gas injection has a tendency to drive acid gas to water-saturated pores. Thus, minor differences are observed in the evolution of pressure buildup (Fig. 7) and gas saturation (Fig. 5).
As with the evolution of gas saturation, pressure buildup has a significant increase at 6,60 , and $300 \mathrm{~m}$, while acid gas is injected for $0.01,1$, and 25 years, respectively. The maximum pressure buildup is generated near the injection well at $0.25,0.275$, and 0.285 bar, respectively. However, an important difference is that pressure buildup is induced at a small value, although the gas saturation remains at zero before acid gas arrives.

During the postinjection time, pressure perturbations decrease gradually over time. The distance of sharp pressure buildup is $343 \mathrm{~m}$ at 100 years and then remains unchanged after 1000 years, which is in accordance with the distance of the gas displacement front. After 10000 years, the pressure of the water-saturated region recovers to its original level, and the value of the two-phase region decreases to 0.08 bar. 


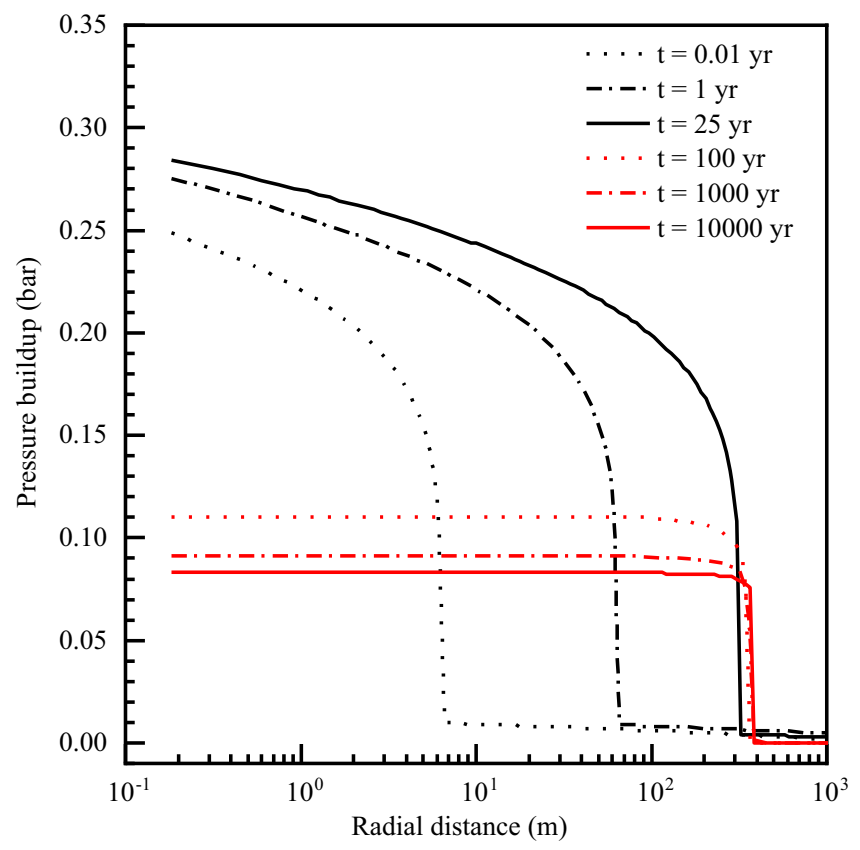

Fig. 7. Evolution of pressure buildup at different times.

\subsection{Geochemical effects}

After injection, acid gas dissolves in the formation water over time, and then undergoes hydrolysis reactions. For the acid gas system, those reactions and their associated equilibrium constants, $\log K_{25^{\circ} \mathrm{C}, 1 \mathrm{bar}}$, are (Xu et al., 2012):

$$
\begin{gathered}
\mathrm{CO}_{2}(\mathrm{aq})+\mathrm{H}_{2} \mathrm{O} \leftrightarrow \mathrm{H}^{+}+\mathrm{HCO}_{3^{-}} \log K_{25^{\circ} \mathrm{C}, 1 \mathrm{bar}}= \\
\log \left(\left[\mathrm{HCO}_{3^{-}}\right]\left[\mathrm{H}^{+}\right] /\left(\left[\mathrm{CO}_{2}(\mathrm{aq})\right]\left[\mathrm{H}_{2} \mathrm{O}\right]\right)\right)=-6.58 \\
\mathrm{HCO}_{3^{-}} \leftrightarrow \mathrm{H}^{+}+\mathrm{CO}_{3}^{2-} \log K_{25^{\circ} \mathrm{C}, 1 \mathrm{bar}}=-10.62 \\
\mathrm{H}_{2} \mathrm{~S}(\mathrm{aq}) \leftrightarrow \mathrm{HS}^{-}+\mathrm{H}^{+} \log K_{25^{\circ} \mathrm{C}, 1 \mathrm{bar}}=-7.42
\end{gathered}
$$

Reactions (6)-(8) all involve $\mathrm{H}^{+}$and then produce an acidic zone where the $\mathrm{pH}$ value tends to decrease. In a highly acidic environment, calcite may dissolve into formation water, consuming $\mathrm{H}^{+}$as subsequent reaction, which partially buffers the system:

$$
\mathrm{CaCO}_{3}+\mathrm{H}^{+} \leftrightarrow \mathrm{Ca}^{2+}+\mathrm{HCO}_{3^{-}}
$$

During acid gas injection, the distributions of $\mathrm{HCO}_{3^{-}}$and $\mathrm{HS}^{-}$concentrations in brine along the radial distance at different times are presented in Figure 8. Since $\mathrm{pH}$ value is the master variable in the system, we plot it as the right-hand axis on the plots.

As described above, the $\mathrm{CO}_{2}$ transport distance is longer than the $\mathrm{H}_{2} \mathrm{~S}$ transport distance in the aqueous phase at each time. Together with Reactions (6)-(8), the $\mathrm{HCO}_{3^{-}}$concentration increases rapidly to $0.93 \mathrm{~mol} / \mathrm{kg} \mathrm{H}_{2} \mathrm{O}$ once the breakthrough front of $\mathrm{CO}_{2}$ arrives. Then, due to the preferential dissolution of $\mathrm{H}_{2} \mathrm{~S}$, the $\mathrm{HCO}_{3^{-}}$concentration decreases gradually to $0.56 \mathrm{~mol} / \mathrm{kg} \mathrm{H}_{2} \mathrm{O}$ as $\mathrm{HS}^{-}$increases
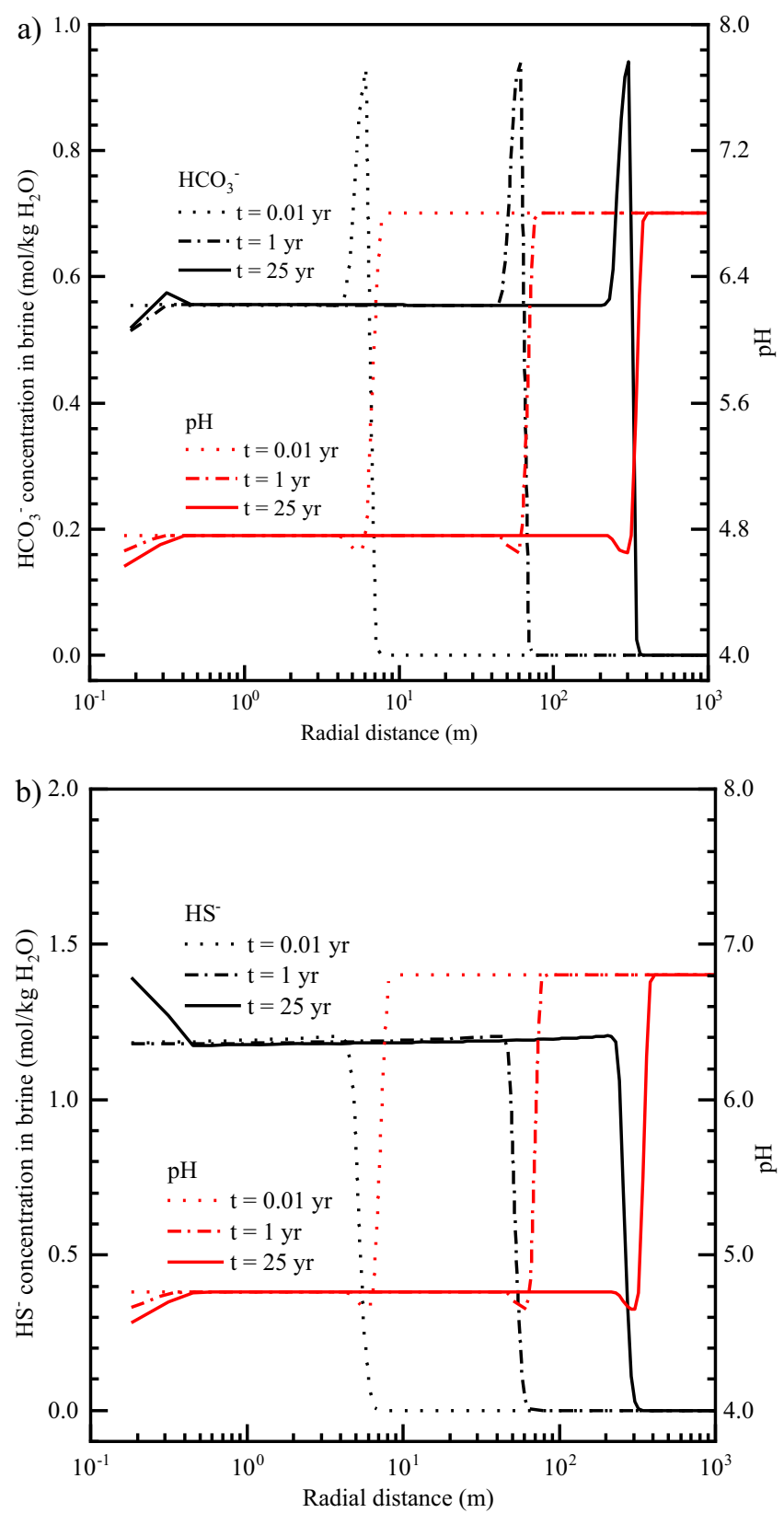

Fig. 8. Aqueous concentration and $\mathrm{pH}$ value at different times during the injection period.

to $1.17 \mathrm{~mol} / \mathrm{kg} \mathrm{H} \mathrm{H}_{2} \mathrm{O}$. The change in calcite abundance is so small (Fig. 10a) that the influence on $\mathrm{pH}$ value can be neglected. $\mathrm{H}_{2} \mathrm{~S}$ generates a weaker acidic solution than that of $\mathrm{CO}_{2}$ since the equilibrium constant of Reaction (8) is smaller than that of Reaction (6). Consequently, the $\mathrm{pH}$ value decreases to 4.65 when the $\mathrm{HCO}_{3^{-}}$concentration increases to the maximum value and subsequently increases to 4.76 due to the weaker acidity of $\mathrm{H}_{2} \mathrm{~S}$.

In the region close to the injection well, a small amount of calcite precipitation occurs after 1 year, reaching a peak value of $1.6 \%$ at a distance of $0.32 \mathrm{~m}$ at 25 years. Calcite precipitation remains constant within a distance of $0.45 \mathrm{~m}$ after 25 years; thus, there is an overlap in that region 

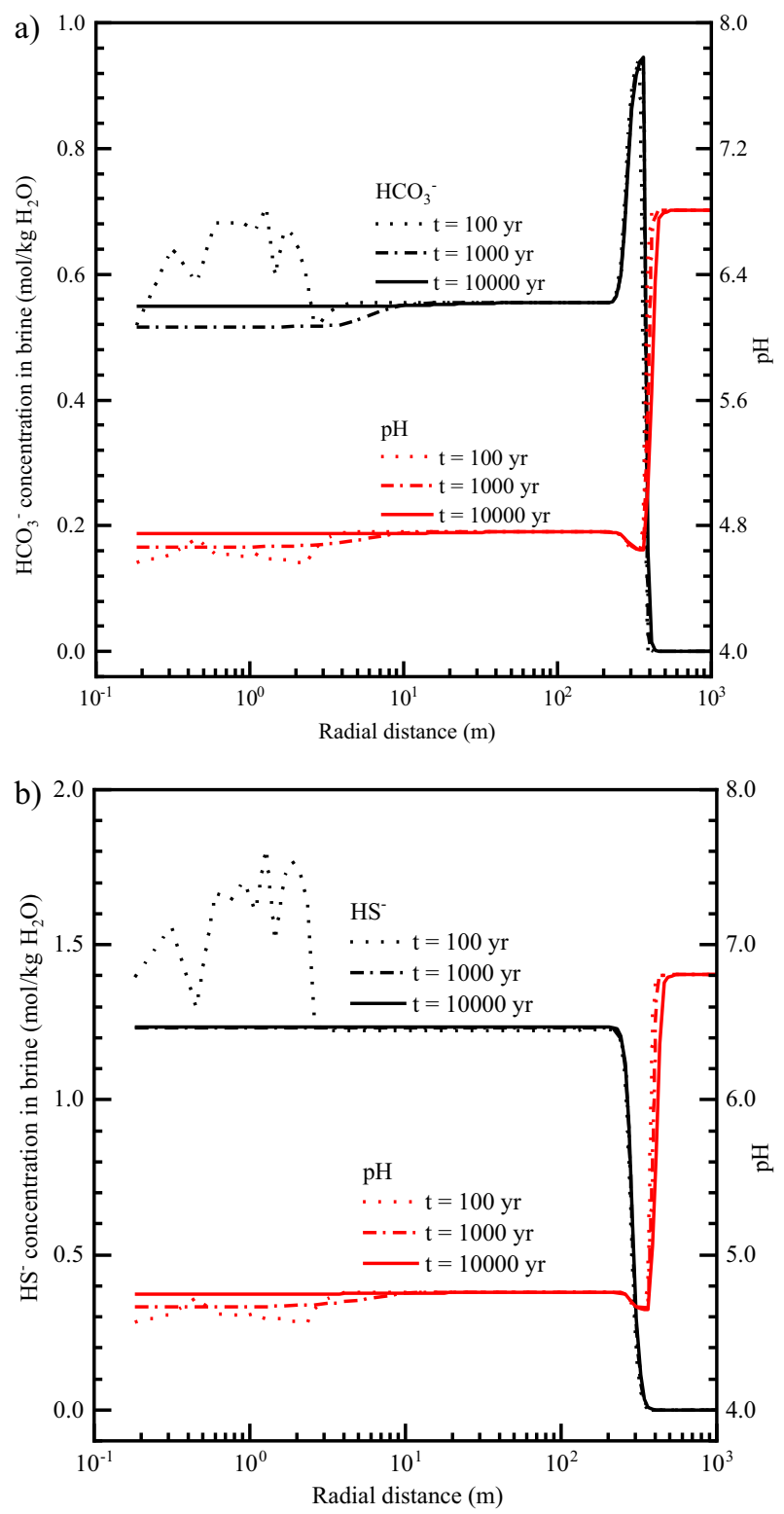

Fig. 9. Aqueous concentration and $\mathrm{pH}$ value at different times during the postinjection period.

among the four curves of 25, 100, 1000, and 10000 years (Fig. 10a). The reverse process of Reaction (9) has a tendency to generate $\mathrm{H}^{+}$and lower the $\mathrm{pH}$ value. At 25 years, the $\mathrm{HCO}_{3^{-}}$concentration reaches $0.52 \mathrm{~mol} / \mathrm{kg}$ $\mathrm{H}_{2} \mathrm{O}$ and that of $\mathrm{HS}^{-}$reaches $1.39 \mathrm{~mol} / \mathrm{kg} \mathrm{H} \mathrm{H}_{2} \mathrm{O}$ when the injection ceases. A pH of approximately 4.57 is attained.

For the acid gas postinjection period, as shown in Figure 9, the distributions of $\mathrm{HCO}_{3^{-}}$and $\mathrm{HS}^{-}$concentrations in the region of the displacement front are very similar to those during the injection period. The $\mathrm{pH}$ value and calcite dissolution also increased. However, in the area close to the injection well, the calcite precipitation region extends to a radius of $2.6 \mathrm{~m}$ (the curves at 10000 years coincide with those at 1000 years on the whole domain). Correspondingly, at 100 years, the $\mathrm{HCO}_{3^{-}}$and $\mathrm{HS}^{-}$concentrations increase
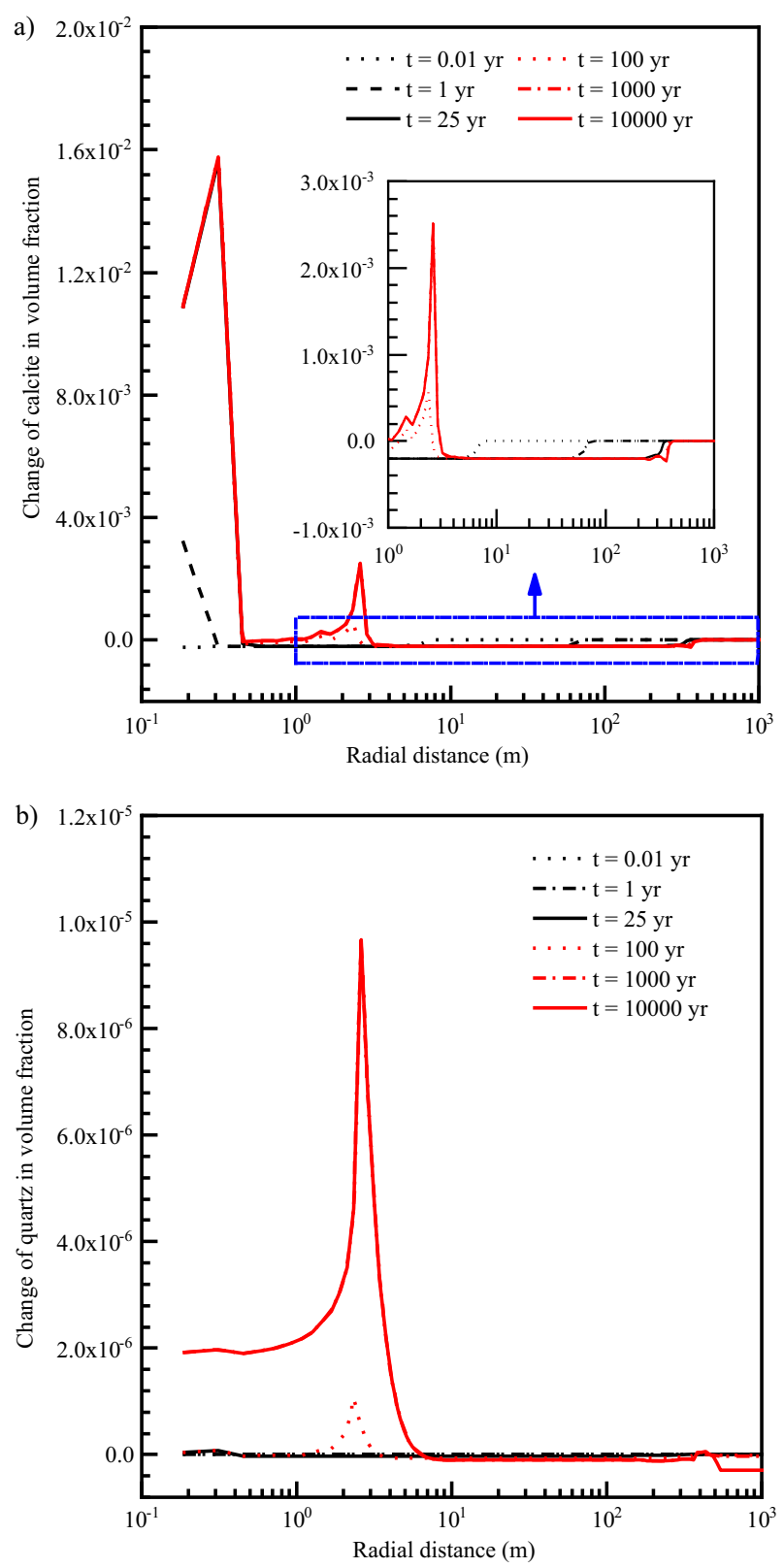

Fig. 10. Changes in (a) calcite and (b) quartz abundances at different times.

significantly, and the $\mathrm{pH}$ value slightly decreases in that region. After that, the aqueous $\mathrm{HCO}_{3^{-}}$and $\mathrm{HS}^{-}$concentrations decrease to $0.55 \mathrm{~mol} / \mathrm{kg} \mathrm{H} \mathrm{H}_{2} \mathrm{O}$ and $1.23 \mathrm{~mol} / \mathrm{kg} \mathrm{H} \mathrm{H}_{2} \mathrm{O}$, respectively. Moreover, a $\mathrm{pH}$ of approximately 4.75 is attained.

Only a marginal increase in quartz content can be observed in Figure 10b, with a peak volume fraction of $10^{-5}$ at a distance of approximately $2.6 \mathrm{~m}$ (the curve at 10000 years coincides with that at 1000 years). Additionally, the precipitation and dissolution amount of calcite are relatively small. Therefore, the variation in porosity is rather small after acid gas injection, as shown in Figure 11. There are irrelevant porosity changes in regard to the hydraulic or mechanical properties of the reservoir. 


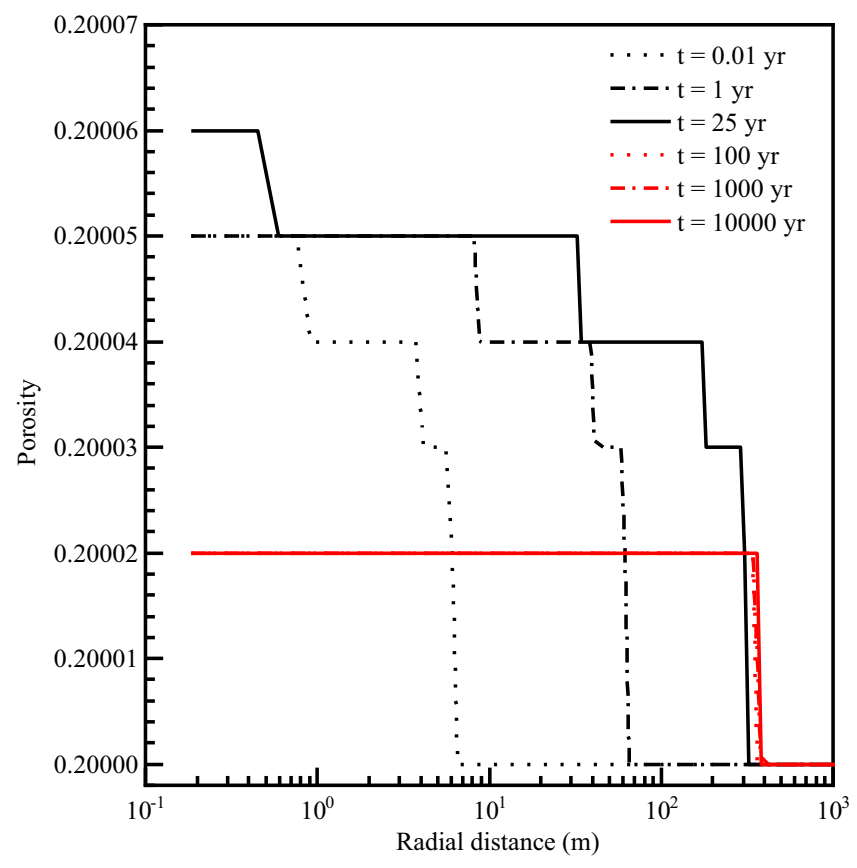

Fig. 11. Evolution of porosity at different times.

Furthermore, the area where porosity varies is consistent with that of the acid gas plume. The irrelevant porosity change is probably a consequence of numerical oscillation.

\subsection{Acid gas trapping evolution}

As with the $\mathrm{CO}_{2}$ trapping mechanism, the acid gas trapping mechanism can be divided into geological trapping, geochemical trapping and hydrodynamic trapping (De Silva et al., 2015; Talman, 2015). Geological trapping includes structural trapping and residual trapping, i.e., mobile acid gas trapped by the formation structure or caprock units and by capillary pressure forces in the pore space. Geochemical trapping is composed of dissolution trapping and mineral trapping, and is thus considered to be a secure trapping mechanism because acid gas can be permanently stored in the formation without leaking to the surface.

For the simulated case, calcite dissolution occurs in the acidic zone, which is caused by the hydrolysis reactions of $\mathrm{CO}_{2}$ and $\mathrm{H}_{2} \mathrm{~S}$ in the region of the displacement front. Therefore, no $\mathrm{CO}_{2}$ or $\mathrm{H}_{2} \mathrm{~S}$ is sequestered in mineral phases during the displacement process; instead, some $\mathrm{CO}_{2}$ and $\mathrm{H}_{2} \mathrm{~S}$ are dissolved. Although calcite is precipitated near the injection well, the amount of precipitation is almost equivalent to that of dissolution. As a result, no $\mathrm{CO}_{2}$ mineral sequestration occurs after acid gas injection. Similarly, no $\mathrm{H}_{2} \mathrm{~S}$ mineral sequestration occurs after acid gas injection. Thus, there are three trapping mechanisms for acid gas, including mobile gas trapping, residual gas trapping and dissolution trapping, as shown in Figure 12.

During acid gas injection, the ratio of dissolved to total injected $\mathrm{H}_{2} \mathrm{~S}$ remains at $62 \%$. In contrast, the ratio of dissolved to total injected $\mathrm{CO}_{2}$ fluctuates from $46 \%$ to $49 \%$,

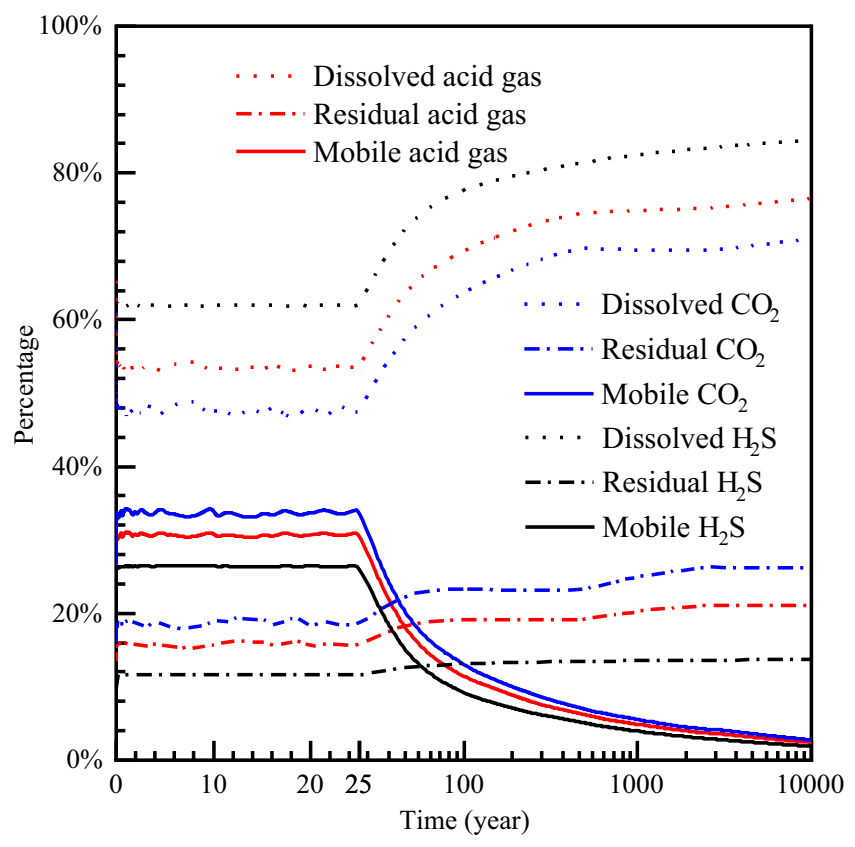

Fig. 12. Evolution of $\mathrm{CO}_{2}, \mathrm{H}_{2} \mathrm{~S}$ and acid gas trapping at different times.

respectively. The variation in dissolution trapping is in line with that of the distribution of $\mathrm{HCO}_{3^{-}}$and $\mathrm{HS}^{-}$concentrations at different times during the injection period shown in Figure 8, which is a result of the preferential dissolution of $\mathrm{H}_{2} \mathrm{~S}$ over $\mathrm{CO}_{2}$. As a result, the ratio of dissolved to total injected acid gas fluctuates from $53 \%$ to $54 \%$, respectively. Similarly, $11.6 \%$ of $\mathrm{H}_{2} \mathrm{~S}$ is residually trapped, $18 \%$ 19\% of $\mathrm{CO}_{2}$ is residually trapped, and $15 \% \sim 16 \%$ of acid gas is thus residually trapped during acid gas injection.

For the acid gas postinjection period, both the residual trapping and dissolution trapping gradually increase, as shown in Figure 12. After a 1000-year storage period, the percentages of dissolution trapping, residual trapping and mobile gas phases for $\mathrm{H}_{2} \mathrm{~S}$ are $84.8 \%, 13.7 \%$, and $1.5 \%$, respectively, and those for $\mathrm{CO}_{2}$ are $71.0 \%, 2.7 \%$, and $26.3 \%$, respectively. Additionally, the percentages of total acid gas injection in solubility trapping, residual trapping and mobile gas trapping are $76.5 \%, 21.1 \%$, and $2.4 \%$, respectively.

\subsection{Sensitivity analysis}

To investigate the numerical model sensitivity to the reservoir parameters porosity, permeability and injection rate, six different cases were considered based on the reservoir parameters. In the first two cases, we changed the injection rate from $19200 \mathrm{Nm}^{3} / \mathrm{d}$ (Base Case) to $38400 \mathrm{Nm}^{3} / \mathrm{d}$ (Case 1) and to $9600 \mathrm{Nm}^{3} / \mathrm{d}$ (Case 2). According to the acid gas composition of the project, acid gas mixtures were injected at a constant rate of $0.458 \mathrm{~kg} / \mathrm{s} \mathrm{CO}_{2}+0.320 \mathrm{~kg} / \mathrm{s}$ $\mathrm{H}_{2} \mathrm{~S}$ in Case 1 and $0.1145 \mathrm{~kg} / \mathrm{s} \mathrm{CO}_{2}+0.080 \mathrm{~kg} / \mathrm{s} \mathrm{H} \mathrm{H}_{2} \mathrm{~S}$ in Case 2. In Cases 3 and 4, the permeability values were changed from $5 \times 10^{-12}$ (Base Case) to $5 \times 10^{-11}$ (Case 3) and to $5 \times 10^{-13}$ (Case 4$)$. Finally, two cases with different 

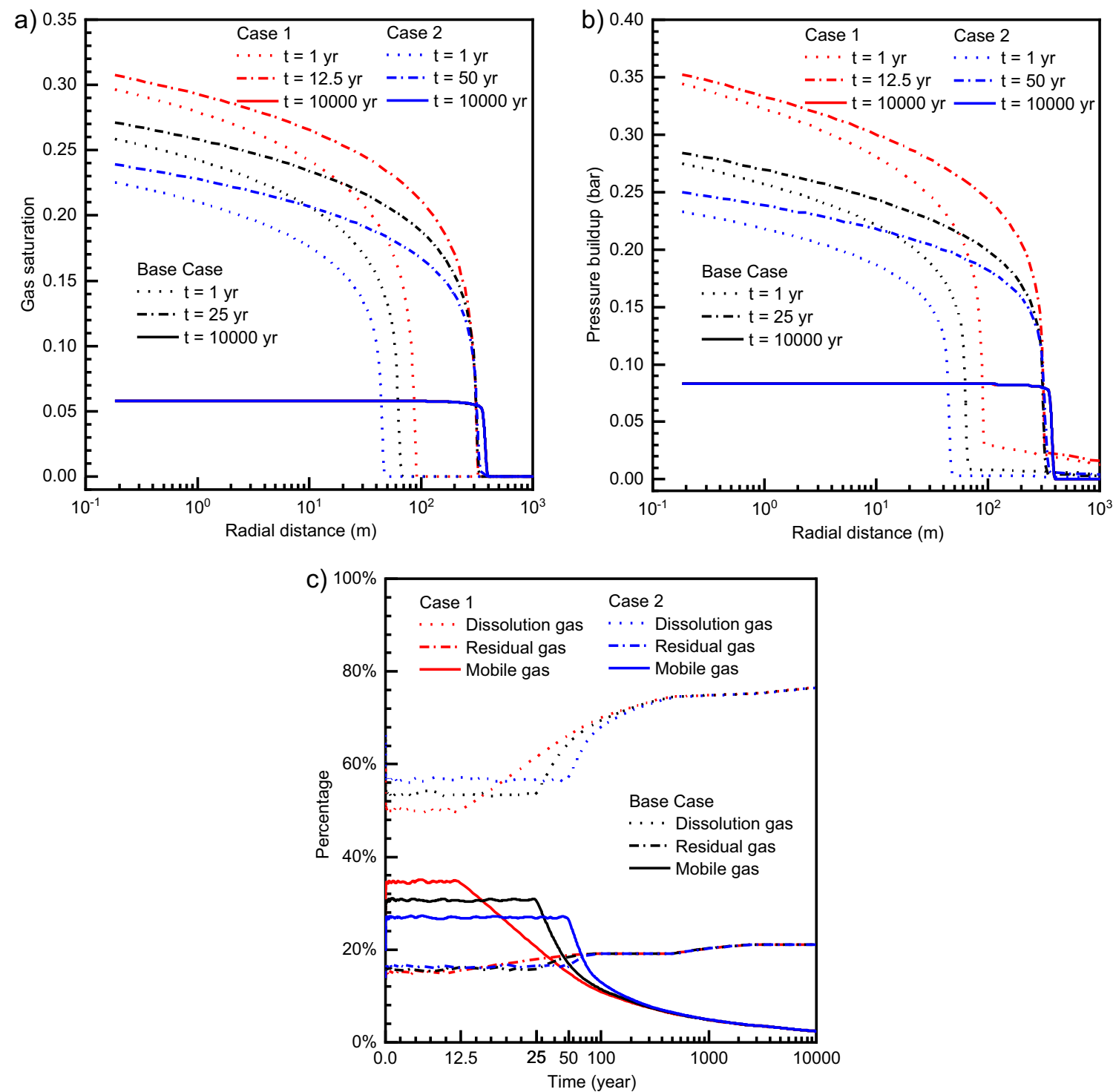

Fig. 13. Effect of injection rate on the (a) gas saturation, (b) pressure buildup at the three selected times and (c) the evolution of acid gas trapping. Note that gas saturation and pressure buildup coincide at 10000 years for the three cases (where Base case, Case 1 and Case 2 indicate that the injection rate values are $0.229 \mathrm{~kg} / \mathrm{s} \mathrm{CO}_{2}+0.160 \mathrm{~kg} / \mathrm{s} \mathrm{H}_{2} \mathrm{~S}, 0.458 \mathrm{~kg} / \mathrm{s} \mathrm{CO} 2+0.320 \mathrm{~kg} / \mathrm{s} \mathrm{H} 2 \mathrm{~S}$ and $0.1145 \mathrm{~kg} / \mathrm{s}$ $\mathrm{CO}_{2}+0.080 \mathrm{~kg} / \mathrm{s} \mathrm{H} \mathrm{H}_{2} \mathrm{~S}$, respectively).

porosities, 0.1 and 0.3, were performed (Cases 5 and 6, respectively). The total volume of acid gas injected in the reservoir is equivalent. Thus, the injection times of Case 1 and Case 2 are changed to 12.5 years and 50 years, respectively. In all other cases (Cases 3-6), the injection time was set as a value of 25 years, which was the same as the Base Case. Furthermore, in all cases, the time of geochemical transport simulations was set to 10000 years.

Figure 13 shows the effect of the injection rate on the gas saturation and pressure buildup at three selected times as well as the evolution of acid gas trapping. The selected times include 1 year during the injection period and 10000 years during the postinjection period in the three cases. The third selected times are $25,12.5$ and 50 in the
Base Case, Case 1 and Case 2, respectively. Figure 13a shows that the gas saturation and migration distance increase during the injection period as the injection rate increases. At the end of acid gas injection, gas saturation is higher with a higher injection rate. However, the migration distances are almost the same. At 10000 years, both the gas saturation and migration distances are the same at the three injection rates. The effect of the injection rate on the pressure buildup is consistent with that of the gas saturation (Fig. 13b). In terms of acid gas trapping, the percentage of dissolution trapping is smaller during the injection period when the injection rate is increased (Fig. 13c). However, the dissolution trapping rate is relatively higher after injection occurs at a higher injection rate. 

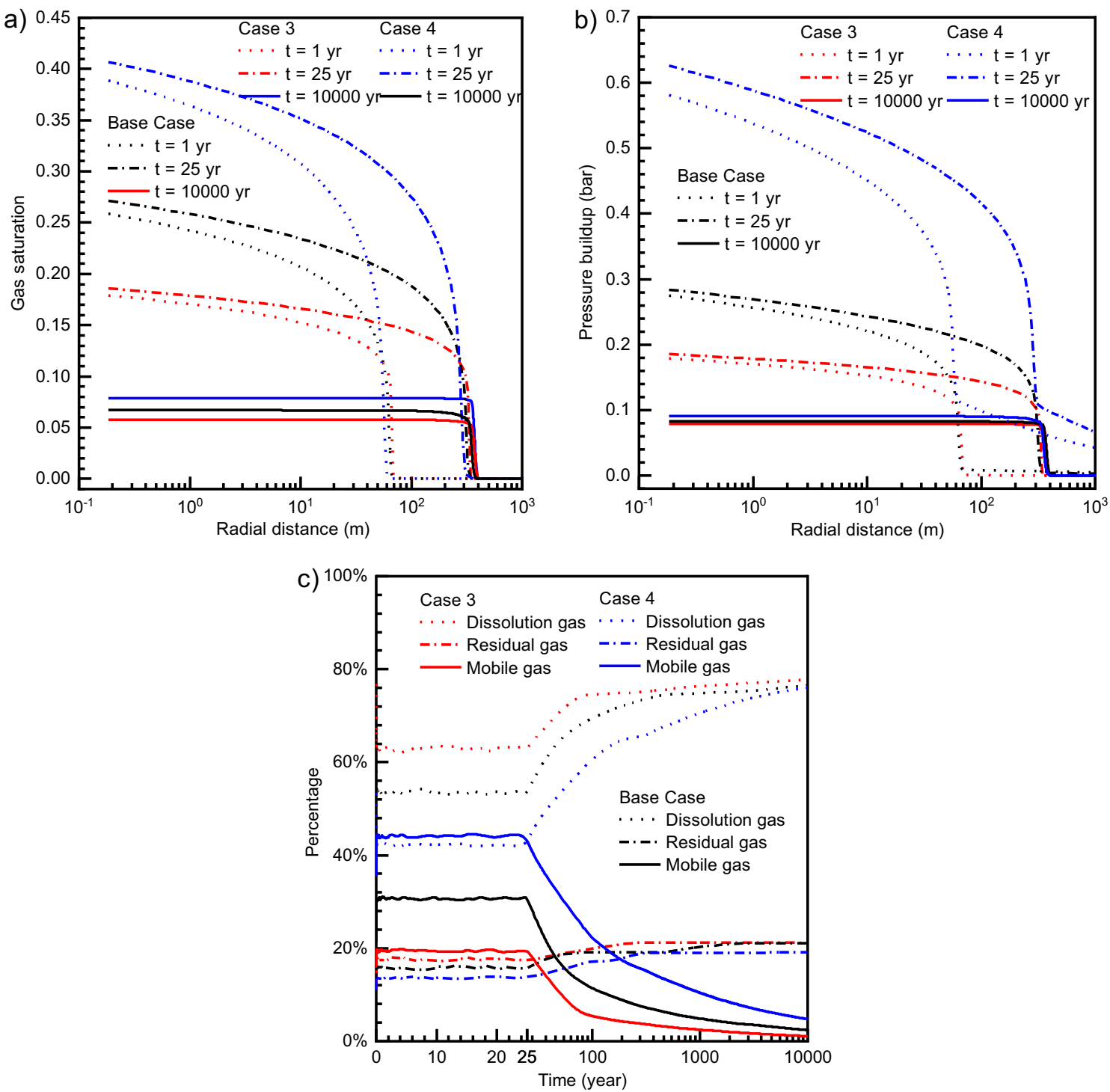

Fig. 14. Effect of permeability on the (a) gas saturation, (b) pressure buildup at the three selected times and (c) the evolution of acid gas trapping (where Base case, Case 3 and Case 4 , indicate that the permeability values are $5 \times 10^{-12}, 5 \times 10^{-11}$ and $5 \times 10^{-13}$, respectively).

The differences in the rate of dissolution trapping for the different injection rates result from the differences in saturation distributions observed at the end of acid gas injection. At higher injection rates, much more acid gas is in the free gas phase. At 10000 years, the same amounts of dissolution trapping are reached at the three injection rates. As shown in Figure 13c, the injection rate has little effect on the residual trapping.

Figure 14 illustrates the effect of permeability on the gas saturation and pressure buildup at three selected times as well as the evolution of acid gas trapping. Gas saturation, pressure buildup and acid gas trapping are significantly affected by permeability. Acid gas will be able to flow through more easily with a higher permeability. Thus, with a higher permeability, the gas saturation is lower and the migration distance is farther. The farther migration distance leads to a larger contact volume between the acid gas and formation water. As a consequence, the dissolution trapping ratio is relatively high at the end of the simulation with high permeability (Fig. 14c). The effect of permeability on pressure buildup is consistent with gas saturation and migration distance (Fig. 14b).

Figure 15 reports the effect of porosity on the gas saturation and pressure buildup at three selected times as well as the evolution of acid gas trapping. Acid gas moves farther when the porosity is reduced (Fig. 15a). The porosity has little effect on the gas saturation and pressure buildup. Additionally, as shown in Figure 15c, the same 

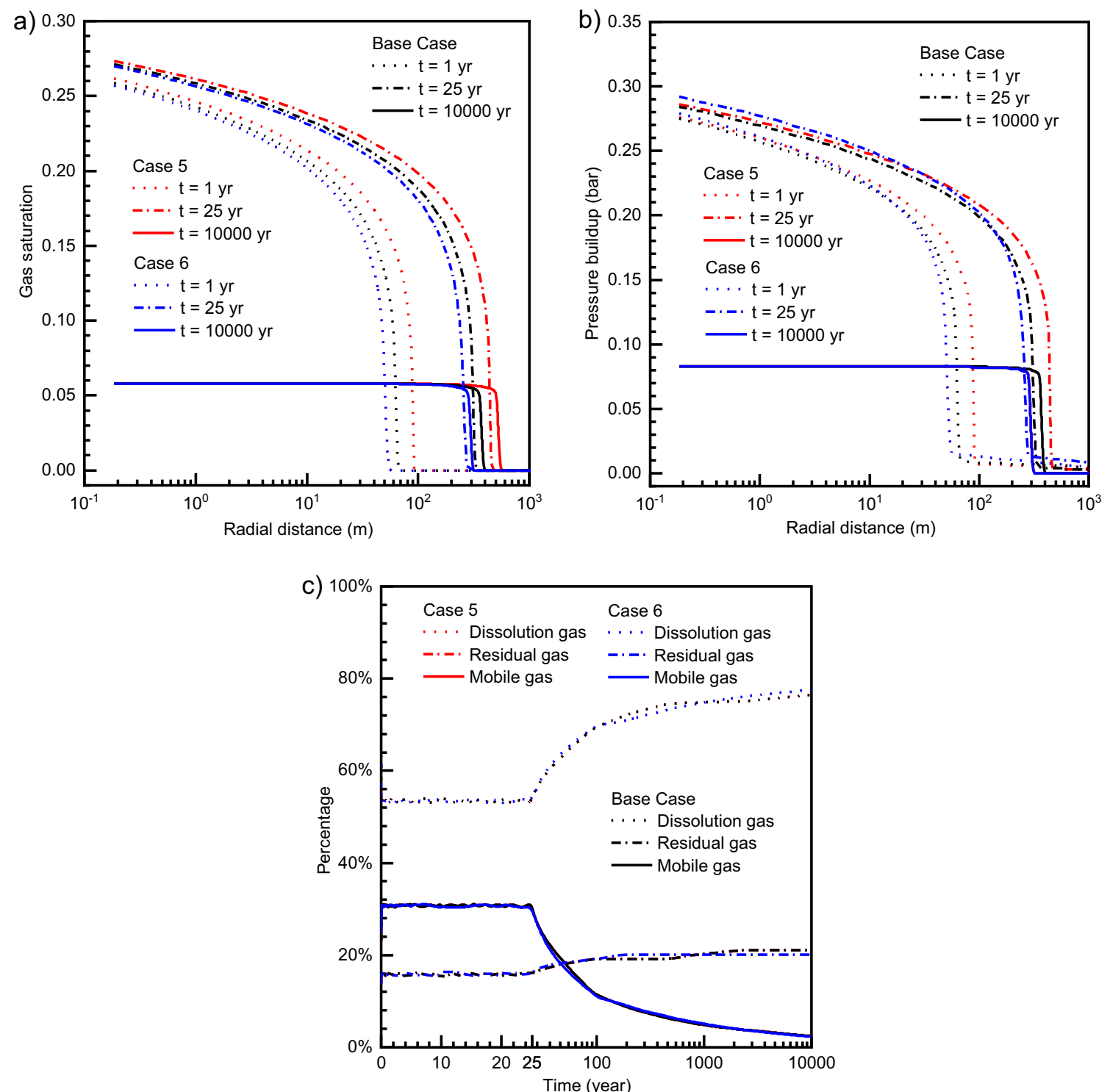

Fig. 15. Effect of porosity on the (a) gas saturation, (b) pressure buildup at the three selected times and (c) the evolution of acid gas trapping. Note that the acid gas trapping curves for Case 5 coincide with those for the Base Case (where Base case, Case 5 and Case 6 indicate that the values of porosity are $0.2,0.1$ and 0.3 , respectively).

amounts of dissolution trapping are reached at the three porosities after acid gas injection.

\section{Discussion}

As investigated in the literature (Meng et al., 2015; Pruess and García, 2002; Pruess and Müller, 2009; Zhao and Cheng, 2017), salt precipitation is caused at the dry-out region near the injection well where liquid saturation is lower than the residual water saturation. The formation porosity and permeability may be reduced by solid salt precipitation. Injectivity impairment will eventually occur after salt accumulation. Under the condition of acid gas injection in this study, the minimum liquid saturation is
0.73 , which is much larger than the residual water saturation $\left(S_{\mathrm{lr}}=0.3\right)$. Thus, there is no dry-out region observed in the reservoir. More importantly, the distribution of liquid saturation is beneficial to engineering operations.

After acid gas injection, the evolution of the $\mathrm{CO}_{2}$ and $\mathrm{H}_{2} \mathrm{~S}$ mass fractions in the gas and aqueous phases indicates that the leading gas front consists of $\mathrm{CO}_{2}$ due to the preferential dissolution of $\mathrm{H}_{2} \mathrm{~S}$ in the aqueous phase. This partitioning phenomenon is consistent with current research (Bachu and Bennion, 2009; Bachu et al., 2009; Zhang et al., 2011; Zheng et al., 2010, 2013). In engineering operations, the quicker breakthrough of $\mathrm{CO}_{2}$ can provide an advanced warning of a potential breakthrough of acid gas. Thus, immediate action should be taken once pure $\mathrm{CO}_{2}$ is detected along the potential leakage pathway. 
The pressure buildup region extends further than that of the acid gas plume, which is in agreement with existing research results (Birkholzer et al., 2009; Liu et al., 2018; Meng et al., 2015). In response to acid gas injection, the fluid pressure in the storage formation reached maximum values of approximately 0.285 bar near the injection zone. According to current practices for the underground injection control of liquid wastes, the maximum allowable injection-induced pressure increase should be limited to reduce the risks of seismic events and geomechanical damage (Bandilla and Celia, 2017; Birkholzer et al., 2009, 2015; Zhou et al., 2010). For example, the regulated injection pressure is limited to $0.181 \mathrm{bar} / \mathrm{m}$ in the Illinois Basin. Correspondingly, the allowable pressure increase needs to be less than $65 \%$ of the preinjection pressure (Bandilla and Celia, 2017; Zhou et al., 2010). In comparison, the maximum pressure buildup of 0.285 bar that was observed in the simulation corresponds to $0.32 \%$ of the preinjection pressure. Consequently, the pressure buildup due to acid gas injection is insignificant to the reservoir.

Only a small increase in quartz is observed after acid gas injection because quartz is relatively stable at $\mathrm{pH}$ values of 2.0-8.5 and below $250{ }^{\circ} \mathrm{C}$ (Li et al., 2016; Xu et al., 2007). In addition, the amounts of calcite precipitation and dissolution are relatively small. Consequently, the porosity is almost unaffected by chemical reactions.

Carbonate rocks have little trapping capacity for $\mathrm{CO}_{2}$ because equilibrium is reached quickly from the accumulation of $\mathrm{Ca}^{2+}$ and $\mathrm{HCO}_{3^{-}}$ions through congruent reactions (Gunter et al., 2000; Zhu et al., 2013). In fact, no $\mathrm{CO}_{2}$ mineral sequestration occurred after acid gas injection in this study. When $\mathrm{H}_{2} \mathrm{~S}$ is injected into iron-rich formations, mineral trapping of $\mathrm{H}_{2} \mathrm{~S}$ is achieved after pyrite reactions occurred (Li et al., 2016; Talman, 2015; Xu et al., 2007). Due to the lack of iron-rich formations in carbonate reservoirs, mineral reactions induced by $\mathrm{H}_{2} \mathrm{~S}$ are not considered and no observed $\mathrm{H}_{2} \mathrm{~S}$ mineral sequestration occurs after acid gas injection. Eventually, there are three trapping mechanisms for acid gas including mobile gas trapping, residual gas trapping and dissolution trapping.

During acid gas injection, the gas saturation and pressure buildup increased considerably with increasing injection rate. As a result, the percentage of the mobile gas phase is larger at a higher injection rate. However, the rate of the mobile gas phase reduced to a minimum is higher. Thus, the injection rate can be increased to facilitate acid gas trapping, which could be used as guidance for acid gas injection.

In the present study, only a 1D model is considered for simplicity in the numerical simulations. In the future, a fully 3D model will be needed for practical storage scenarios.

\section{Conclusion}

The possible impact of acid gas injection has been successfully evaluated through numerical modeling of a conceptual model with the hydrologic properties and mineral compositions of the target Tarim Basin reservoir, the possible impact of acid gas injection has been successfully evaluated. The major conclusions are as follows:

1. The maximum gas saturation of 0.27 is achieved at the end of injection, which is beneficial to engineering operations. At 10000 years, the gas saturation tends to reach 0.05. In addition, the preferential dissolution of $\mathrm{H}_{2} \mathrm{~S}$ delays its breakthrough compared to that of $\mathrm{CO}_{2}$ both in the gas and aqueous phases, and the maximum $\mathrm{CO}_{2}$ mass fraction is almost 1 . This finding has great implications for detecting and providing advanced warning of the potential leakage of acid gas.

2. During the injection period, the maximum pressure buildup is generated at 0.285 bar near the injection well at 25 years, and a slight increase in pressure is observed at the region where the acid gas has not yet arrived. After 10000 years, 0.08 bar of pressure buildup is achieved within the distance at which acid gas arrives, and pressure is recovered to the original level out of that distance. The maximum pressure buildup of 0.285 bar that was observed in the simulation corresponds to $0.32 \%$ of the preinjection pressure. Consequently, the pressure buildup that occurred due to acid gas injection has little effect on the reservoir.

3. At the displacement front, the amount of calcite precipitation is small enough to neglect. The concentration of $\mathrm{HCO}_{3^{-}}$first increases and then decreases due to the preferential dissolution of $\mathrm{H}_{2} \mathrm{~S}$. Because $\mathrm{H}_{2} \mathrm{~S}$ generates a weaker acidic solution than $\mathrm{CO}_{2}$, the $\mathrm{pH}$ value decreases to 4.65 and subsequently increases to 4.76 . In the region close to the injection well, a small amount of calcite precipitation occurs during the acid gas injection, and thus, a minimum $\mathrm{pH}$ value of approximately 4.57 is attained. The calcite precipitation region near the injection well extends largely after the acid gas injection ceases, and thus, there is a slight reduction in $\mathrm{pH}$ value in that region at 100 years. At the end of the simulation, a $\mathrm{pH}$ of approximately 4.75 is attained. In addition, the variation in porosity is relatively small after acid gas injection due to the small changes in calcite and quartz in the volume fraction.

4. There are three trapping mechanisms: mobile gas trapping, residual gas trapping and dissolution trapping. As a secure trapping mechanism, the ratio of dissolved $\mathrm{H}_{2} \mathrm{~S}$ to total injected $\mathrm{H}_{2} \mathrm{~S}$ is higher than that of $\mathrm{CO}_{2}$ during acid gas injection. At the end of acid gas injection, $54 \%$ of acid gas is trapped by dissolution trapping, and $76.5 \%$ is trapped at the end of simulation.

5. There is a higher rate of mobile gas phase decreasing to the minimum amount with a higher injection rate. The injection rate can be increased to facilitate acid gas trapping, which could be used as guidance for acid gas injection.

6. The porosity has little effect on the gas saturation, pressure buildup and trapping mechanism. However, gas saturation, pressure buildup and acid gas trapping are significantly affected by permeability. Under a higher permeability, the gas saturation is lower and 
the migration distance is farther. Correspondingly, the mobile phase ratio is lower at the end of the simulation.

In summary, the distribution of acid gas is beneficial to acid gas injection. Moreover, the pressure buildup is under the allowable pressure increase. Additionally, the porosity change is negligible due to small changes in calcite and quartz in the volume fraction. In conclusion, our simulation indicates that acid gas injection is feasible in the carbonate formation of the Tarim Basin.

Acknowledgments. The authors wish to thank Prof. Simon Mathias of Durham University for his improvements in grammar and readability. The authors also wish to thank the two anonymous reviewers for their constructive suggestions for improving the quality of the manuscript. Special thanks to Guizhen Liu for her map illustration. This work was partially supported by the National Natural Science Foundation of China (Grant Nos. 41872210, 41274111) and SINOPEC Northwest Oilfield Branch (Grant No. 34400007-17-ZC0607-0172)

\section{References}

Bachu S., Bennion D.B. (2009) Chromatographic partitioning of impurities contained in a $\mathrm{CO}_{2}$ stream injected into a deep saline aquifer: Part 1. Effects of gas composition and in situ conditions, Int. J. Greenhouse Gas Control 3, 4, 458-467.

Bachu S., Gunter W.D. (2004) Overview of acid-gas injection operations in western Canada, Seventh International Conference on Greenhouse Gas Control Technologies (GHGT-7), Vancouver, Canada, pp. 1-6.

Bachu S., Pooladi-Darvish M., Hong H. (2009) Chromatographic partitioning of impurities $\left(\mathrm{H}_{2} \mathrm{~S}\right)$ contained in a $\mathrm{CO}_{2}$ stream injected into a deep saline aquifer: Part 2. Effects of flow conditions, Int. J. Greenhouse Gas Control 3, 4, 468-473.

Bacon D.H., Ramanathan R., Schaef H.T., Mcgrail B.P. (2014) Simulating geologic co-sequestration of carbon dioxide and hydrogen sulfide in a basalt formation, Int. J. Greenhouse Gas Control 21, 2, 165-176.

Bandilla K.W., Celia M.A. (2017) Active pressure management through brine production for basin-wide deployment of geologic carbon sequestration, Int. J. Greenhouse Gas Control 61, 155-167.

Bierlein J.A., Kay W.B. (1953) Phase-equilibrium properties of system carbon dioxide-hydrogen sulfide, Ind. Eng. Chem. 45, $3,618-624$.

Birkholzer J.T., Oldenburg C.M., Zhou Q. (2015) $\mathrm{CO}_{2}$ migration and pressure evolution in deep saline aquifers, Int. J. Greenhouse Gas Control 40, 203-220.

Birkholzer J.T., Zhou Q., Tsang C.-F. (2009) Large-scale impact of $\mathrm{CO}_{2}$ storage in deep saline aquifers: A sensitivity study on pressure response in stratified systems, Int. J. Greenhouse Gas Control 3, 2, 181-194.

British Columbia Geological Survey (2003) Acid gas injection: A study of existing operations phase I: Final report, Ministry of Energy, Mines and Petroleum Resources, British Columbia Geological Survey, p. 71.

Cantucci B., Montegrossi G., Buttinelli M., Vaselli O., Scrocca D., Quattrocchi F. (2015) Geochemical barriers in $\mathrm{CO}_{2}$ capture and storage feasibility studies, Transp. Porous Media 106, 1, 107-143.

Carroll J.J., Griffin P.J., Alkafeef S.F. (2009) Review and outlook of subsurface acid gas disposal, in: SPE Middle East Oil and Gas Show and Conference, Society of Petroleum Engineers, Manama, Bahrain, p. 10.

Chen H., Yang S., Dong C., Zhu G., Jia C., Wei G., Wang Z. (1997) Geological thermal events in Tarim basin, Chin. Sci. Bull. 07, 580-584.

De Silva G.P.D., Ranjith P.G., Perera M.S.A. (2015) Geochemical aspects of $\mathrm{CO}_{2}$ sequestration in deep saline aquifers: A review, Fuel 155, 128-143.

Gao Z., Liu Z., Gao S., Ding Q., Wu S., Liu S. (2016) Characteristics and genetic models of lower Ordovician carbonate reservoirs in southwest Tarim basin, NW China, J. Pet. Sci. Eng. 144, 99-112.

Gunter W.D., Perkins E.H., Hutcheon I. (2000) Aquifer disposal of acid gases: Modelling of water-rock reactions for trapping of acid wastes, Appl. Geochem. 15, 8, 1085-1095.

Jia L., Cai C., Jiang L., Zhang K., Li H., Zhang W. (2016) Petrological and geochemical constraints on diagenesis and deep burial dissolution of the Ordovician carbonate reservoirs in the Tazhong area, Tarim basin, NW China, Mar. Pet. Geol. 78, 271-290.

Khan C., Amin R., Madden G. (2013) Effects of $\mathrm{CO}_{2}$ and acid gas injection on enhanced gas recovery and storage, Journal of Petroleum Exploration and Production Technology 3, 1, 55-60.

Knauss K.G., Johnson J.W., Steefel C.I. (2005) Evaluation of the impact of $\mathrm{CO}_{2}$, co-contaminant gas, aqueous fluid and reservoir rock interactions on the geologic sequestration of $\mathrm{CO}_{2}$, Chem. Geol. 217, 3, 339-350.

Lasaga A.C., Soler J.M., Ganor J., Burch T.E., Nagy K.L. (1994) Chemical weathering rate laws and global geochemical cycles, Geochim. Cosmochim. Acta 58, 10, 2361-2386.

Li C., Zhang F., Lyu C., Hao J., Song J., Zhang S. (2016) Effects of $\mathrm{H}_{2} \mathrm{~S}$ injection on the $\mathrm{CO}_{2}$-brine-sandstone interaction under $21 \mathrm{MPa}$ and $70^{\circ} \mathrm{C}$, Mar. Pollut. Bull. 106, 1, 17-24.

Li Q., Li X., Niu Z., Kuang D., Ma J., Liu X., Sun Y., Li X. (2017) Effects of acid gas reinjection on enhanced natural gas recovery and carbon dioxide geological storage: Investigation of the right bank of the amu darya river, In: Y. Wu, J.J. Carroll, W. Zhu (eds), Carbon dioxide capture and acid gas injection. Advances in natural gas engineering, Wiley, New York, pp. 221-244. doi: 10.1002/9781118938706.ch12.

Li Q., Liu X., Du L., Bai B., Fang Z., Jing M., Li X. (2013) Economics of acid gas reinjection with comparison to sulfur recovery in China, Energy Procedia 37, 2505-2510.

Liang S., Deng Y., Zhou W. (2016) Optimization selection of injecting $\mathrm{N}_{2}$ volume in single well of Tahe fractured vuggy reservoir, Drill. Prod. Technol. 39, 4, 60-62.

Liu B., Xu J., Li Z., Malekian R., Xu Z. (2018) Modeling of $\mathrm{CO}_{2}$ transport and pressure buildup in reservoirs during $\mathrm{CO}_{2}$ storage in saline aquifers: A case in Dongying Depression in China, Environ. Earth Sci. 77, 5, 158.

Liu X., Li Q., Du L., Li X. (2012) Economic comparison of both acid-gas reinjection and sulfur recovery in high-sour gasfields, Natural Gas Technol. Econ. 6, 4, 55-59.

Marini L. (2006) Geological sequestration of carbon dioxide: Thermodynamics, kinetics, and reaction path modeling, Elsevier.

Meng Q., Jiang X., Li D., Xie Q. (2015) Numerical simulations of pressure buildup and salt precipitation during carbon dioxide storage in saline aquifers, Comput. Fluids 121, 92-101. 
Miwa M., Shiozawa Y., Saito Y., Tarmoom I.O. (2002) Sour gas injection project, in: Abu Dhabi International Petroleum Exhibition and Conference, Society of Petroleum Engineers, Abu Dhabi, United Arab Emirates, p. 11.

Palandri J.L., Kharaka Y.K. (2004) A compilation of rate parameters of water-mineral interaction kinetics for application to geochemical modeling, Geological Survey Menlo Park, CA.

Pruess K., Battistelli A. (2002) TMVOC, a numerical simulator for three-phase non-isothermal flows of multicomponent hydrocarbon mixtures in saturated-unsaturated heterogeneous media, Earth Sciences Division, Lawrence Berkeley National Laboratory.

Pruess K., García J. (2002) Multiphase flow dynamics during $\mathrm{CO}_{2}$ disposal into saline aquifers, Environmental Geology 42, 2, 282-295.

Pruess K., Müller N. (2009) Formation dry-out from $\mathrm{CO}_{2}$ injection into saline aquifers: 1 . Effects of solids precipitation and their mitigation, Water Resour. Res. 45, 3.

Reagan M. (2006) WebGasEOS 1.0 user guide, Earth Sciences Division, Lawrence Berkeley National Laboratory.

Schaef H.T., McGrail B.P., Owen A.T. (2010) Carbonate mineralization of volcanic province basalts, Int. J. Greenhouse Gas Control 4, 2, 249-261.

Schaef H.T., Mcgrail B.P., Owen A.T., Arey B.W. (2013) Mineralization of basalts in the $\mathrm{CO}_{2}-\mathrm{H}_{2} \mathrm{O}-\mathrm{H}_{2} \mathrm{~S}$ system, Int. $J$. Greenhouse Gas Control 16, 4, 187-196.

Shen A., Zheng J., Chen Y., Ni X., Huang L. (2016) Characteristics, origin and distribution of dolomite reservoirs in Lower-Middle Cambrian, Tarim basin, NW China, Pet. Explor. Dev. 43, 3, 375-385.

Talman S. (2015) Subsurface geochemical fate and effects of impurities contained in a $\mathrm{CO}_{2}$ stream injected into a deep saline aquifer: What is known, Int. J. Greenhouse Gas Control 40, 267-291.

Xiao Y., Xu T., Pruess K. (2009) The effects of gas-fluid-rock interactions on $\mathrm{CO}_{2}$ injection and storage: Insights from reactive transport modeling, Energy Procedia 1, 1, 17831790.
Xu T., Apps J.A., Pruess K., Yamamoto H. (2007) Numerical modeling of injection and mineral trapping of $\mathrm{CO}_{2}$ with $\mathrm{H}_{2} \mathrm{~S}$ and $\mathrm{SO}_{2}$ in a sandstone formation, Chem. Geol. 242, 3, 319-346.

$\mathrm{Xu}$ T., Spycher N., Sonnenthal E., Zheng L., Pruess K. (2012) Toughreact user's guide: A simulation program for nonisothermal multiphase reactive geochemical transport in variably saturated geologic media, version 2.0, Earth Sciences Division, Lawrence Berkeley National Laboratory, University of California, Berkeley, CA, p. 94720.

Yu Q., Wen Z., Tang Y. (2011) Geochemical characteristics of Ordovician crude oils in the northwest of the Tahe oil field, Tarim basin, Chin. J. Geochem. 30, 1, 93-98.

Zhang W., Xu T., Li Y. (2011) Modeling of fate and transport of coinjection of $\mathrm{H}_{2} \mathrm{~S}$ with $\mathrm{CO}_{2}$ in deep saline formations, $J$. Geophys. Res. Solid Earth 116, B02202.

Zhao R., Cheng J. (2017) Effects of temperature on salt precipitation due to formation dry-out during $\mathrm{CO}_{2}$ injection in saline aquifers, Greenhouse Gases Sci. Technol. 7, 4, 624-636.

Zheng L., Spycher N., Birkholzer J., Xu T., Apps J., Kharaka Y. (2013) On modeling the potential impacts of $\mathrm{CO}_{2}$ sequestration on shallow groundwater: Transport of organics and co-injected $\mathrm{H}_{2} \mathrm{~S}$ by supercritical $\mathrm{CO}_{2}$ to shallow aquifers, Int. J. Greenhouse Gas Control 14, 113-127.

Zheng L., Spycher N., Xu T., Apps J., Kharaka Y., Birkholzer J. T. (2010) Modeling studies on the transport of Benzene and $\mathrm{H}_{2} \mathrm{~S}$ in $\mathrm{CO}_{2}$-water systems, Office of Scientific \& Technical Information Technical Reports.

Zhou Q., Birkholzer J.T., Mehnert E., Lin Y.-F., Zhang K. (2010) Modeling basin- and plume-scale processes of $\mathrm{CO}_{2}$ storage for full-scale deployment, Groundwater 48, 4, 494-514.

Zhu J., Parris T.M., Richard Bowersox J., Harris D.C. (2013) Modeling $\mathrm{CO}_{2}$-brine-rock interactions in the knox group: Implications of a deep carbon storage field test in western Kentucky, Appl. Geochem. 37, 29-42.

Ziabakhsh-Ganji Z., Kooi H. (2012) An equation of state for thermodynamic equilibrium of gas mixtures and brines to allow simulation of the effects of impurities in subsurface $\mathrm{CO}_{2}$ storage, Int. J. Greenhouse Gas Control 11, S21-S34. 